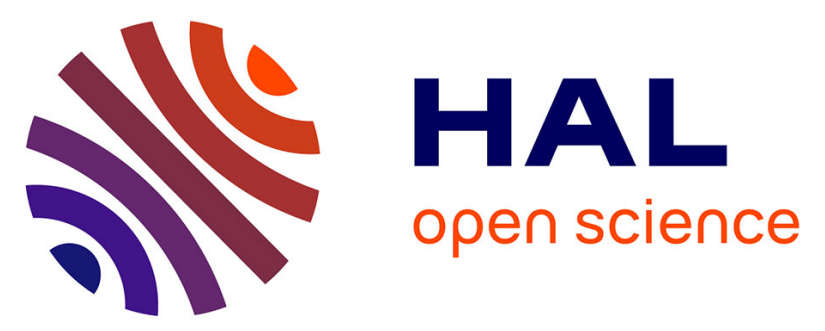

\title{
Effects of tungsten alloying and the fluorination on the oxidation behavior of intermetallic titanium aluminides for aerospace applications
}

\author{
Alexander Donchev, Lukas Mengis, Alain Couret, Svea Mayer, Helmut \\ Clemens, Mathias Galetz
}

\section{To cite this version:}

Alexander Donchev, Lukas Mengis, Alain Couret, Svea Mayer, Helmut Clemens, et al.. Effects of tungsten alloying and the fluorination on the oxidation behavior of intermetallic titanium aluminides for aerospace applications. Intermetallics, 2021, 139, 10.1016/j.intermet.2021.107270 . hal-03389558

\section{HAL Id: hal-03389558 https://hal.science/hal-03389558}

Submitted on 21 Oct 2021

HAL is a multi-disciplinary open access archive for the deposit and dissemination of scientific research documents, whether they are published or not. The documents may come from teaching and research institutions in France or abroad, or from public or private research centers.
L'archive ouverte pluridisciplinaire HAL, est destinée au dépôt et à la diffusion de documents scientifiques de niveau recherche, publiés ou non, émanant des établissements d'enseignement et de recherche français ou étrangers, des laboratoires publics ou privés. 
Effects of tungsten alloying and the fluorination on the oxidation behavior of intermetallic titanium aluminides for aerospace applications

\author{
Alexander Donchev ${ }^{1}{ }^{*}$, Lukas Mengis ${ }^{1}$, Alain Couret $^{2}$, Svea Mayer ${ }^{3}$, Helmut Clemens ${ }^{3}$, Mathias \\ Galetz $^{1}$ \\ ${ }^{1}$ DECHEMA-Forschungsinstitut, Theodor-Heuss-Allee 25, 60486 Frankfurt am Main/Germany \\ ${ }^{2}$ CEMES-CNRS, 29 Rue Jeanne Marvig, 31055 Toulouse/France \\ ${ }^{3}$ Department Materials Science, Montanuniversität Leoben, Franz-Josef Str. 18, 8700 Leoben/ \\ Austria \\ *corresponding author, donchev@ dechema.de, +49697564386
}

\begin{abstract}
Current limitations to a wider use of intermetallic TiAl alloys in aircraft and automotive engines arise from an insufficient oxidation resistance at temperatures above approximately $800^{\circ} \mathrm{C}$. In this paper, the high temperature oxidation behavior of three engineering $\gamma$-TiAl-based alloys at $900^{\circ} \mathrm{C}$ in air is reported. The performance of the TNM alloy (Ti-43.5Al-4Nb-1Mo-0.1B), the 4822 alloy (Ti-48Al-2Cr-2Nb), and the Nb-free IRIS alloy (Ti-48Al-2W-0.08B) is compared (all chemical compositions are given in at.\%). During testing in air non-protective mixed oxide scales developed on all untreated samples, but with different compositions and thicknesses. These different oxide layers are characterized and their formation mechanisms are discussed. The presence of $\mathrm{W}$ in the IRIS alloy leads to a better oxidation behavior compared to untreated TNM and 4822. This behavior was changed in the direction of a protective alumina layer formation via the so-called "fluorine effect". The above-mentioned alloys were treated with fluorine via a liquid phase process by evenly spraying a fluorine containing polymer on all faces of the specimens. The oxidation resistance of the fluorine treated samples was significantly improved compared to the untreated specimens. Due to the fluorination all treated test coupons exhibited slow oxidation kinetics. The results of isothermal as well as thermocyclic exposure tests are presented and discussed in the view of the chemical composition and processing conditioned microstructure of the three investigated $\gamma$-TiAl-based alloys.
\end{abstract}

\title{
Keywords
}
A. intermetallics (aluminides, silicides)
B. oxidation
C. coatings
F. microscopy, various
G. aero-engine components; automotive uses, including engines (and other transportation uses)




\section{Highlights}

- Comparison of the engineering $\gamma$-TiAl-based alloys TNM, 4822 and IRIS with regard to their oxidation resistance

- Positive effect of W in the IRIS alloy is leading to reduced spallation

- Improvement of the oxidation resistance for all tested technical $\gamma$-TiAl-based alloys via the fluorine effect

- No effect of the different microstructures and chemical compositions on the fluorine effect efficiency

- Possible application at high temperatures above $800^{\circ} \mathrm{C}$ after a fluorine treatment

\section{Introduction}

The human impact on the climate change triggers the demand for advanced automotive or jet engines with higher efficiency, i.e. reduced fuel consumption and lower $\mathrm{CO}_{2}$ and $\mathrm{NO}_{\mathrm{x}}$ emissions, than the ones currently used. In addition to new and improved design concepts, a possibility to reach this goal is the use of light-weight materials which allow faster rotating speeds and shorter ramp-up times. Hence, the use of innovative structural materials, such as intermetallic $\gamma$-TiAlbased alloys, may play a decisive role since they can replace currently used heavier Ni- or Cobased alloys with only half of their density (ca. $4 \mathrm{~g} / \mathrm{cm}^{3}$ ) [1-4].

Cast TiAl blades already have been introduced in the low-pressure turbine of General Electric's GEnX jet engine in 2011 [1] and recently by Pratt \& Whitney in the as-forged condition in the Geared Turbofan engine [5]. An industrial exploitation of these alloys on a larger scale requires addressing two major issues. One of them concerns the room temperature (RT) ductility along with high temperature creep strength. The other one is the resistance against environmental damage at elevated temperatures. Research and development activities have led to high-strength alloys with a fraction of $\beta_{\mathrm{o}}$-phase besides the $\gamma$ - and $\alpha_{2}$-phase, i.e. complex multi-phase alloys of the $4^{\text {th }}$ generation, which represent the class of process-adapted TiAl alloys, see $[3,6]$ and the references cited in this review paper. They possess an improved hot-workability and balanced mechanical properties which allow long-term use as advanced high-temperature material up to temperatures of about $750^{\circ} \mathrm{C}$. In the future an increase of the operation temperature of $\mathrm{TiAl}$ components is planned but currently the use is impeded by an insufficient oxidation resistance [7]. Despite an $\mathrm{Al}$ content of above 40 at.\%, TiAl alloys do not form an alumina layer. Reasons for this are the similar thermodynamic stabilities of Ti- and Al-oxides and the low Al-activity within the alloy system, e.g. see [8]. Hence, a mixed oxide scale develops during hightemperature exposure in air, which is non-protective and grows fast due to the high kinetics of the $\mathrm{TiO}_{2}$ formation [9]. The mixed scale can spall if a certain stress level is reached [10]. This leads to an accelerated material loss and a shortage of TiAl component lifetime. In the course of alloy development, further element additions, which chiefly affects the mechanical properties of the bulk material [11], can improve the oxidation behavior of TiAl alloys, but cannot prevent environmental damage during long term exposure at temperatures above $800^{\circ} \mathrm{C}$. For example, $\mathrm{Nb}$ additions up to about 10 at. $\%$ can improve the oxidation resistance of these alloys, but do not impede the growth of a mixed scale [12]. Mo additions up to 2 at.\% are also beneficial, but with the same restrictions [13,14]. A higher Mo content shows 
an inferior oxidation behavior $[15,16]$. The results concerning the effect of $\mathrm{Cr}$ on the oxidation behavior revealed a detrimental behavior [17] while for $\mathrm{W}$ a positive effect was found [18].

However, there are also other ways to overcome the oxidation problems, e.g. the use of coatings [19].This is not an easy task for TiAl due to the formation of brittle intermetallic phases. The socalled "fluorine effect", which is a surface modification technique, is an alternative solution. It has been proven to dramatically increase the oxidation resistance of technical TiAl alloys with an $\mathrm{Al}$ content above 40 at.\% during high temperature exposure up to temperatures of $1050^{\circ} \mathrm{C}[20$, 21]. Hereby, very small amounts of fluorine at the metal/oxide interface lead to the formation of a protective alumina barrier [22]. It protects the material even in water vapor containing environments as well as under thermocyclic conditions [23]. Nevertheless, the effect of chemical composition and phase constitution on the efficiency of the fluorine effect has not been systematically studied up to now.

In this paper three engineering $\gamma$-TiAl-based alloys for aerospace applications are investigated, namely the TNM [3], the 4822 [24] and the Nb-free IRIS alloy [25]. The results of isothermal and thermocyclic high temperature exposure experiments on untreated and F-treated specimens of the three TiAl alloys with different chemical compositions and microstructures are presented. The obtained results are discussed in view of a potential use of such multi-phase alloys at operating temperatures higher than $750^{\circ} \mathrm{C}$.

\section{Experimental}

Specimens of the TiAl alloy variants TNM and 4822 were produced by ingot metallurgy via vacuum arc remelting and centrifugal casting in permanent molds by GfE Metalle und Materialien GmbH, Nuremberg, Germany [6]. Subsequently, the ingots were hot-isostatically pressed (HIPed) and slowly cooled to RT. The third alloy variant was produced by powder metallurgy via spark-plasma-sintering (SPS) at CEMES, Toulouse, France [26]. The nominal chemical compositions are as following: Ti-43.5Al-4Nb-1Mo-0.1B (TNM), Ti-48Al-2Nb-2Cr (4822) and Ti-48Al-2W-0.08B (IRIS) (in at.\%).

High temperature oxidation tests were performed on coupons of $15 \times 10 \times 1 \mathrm{~mm}^{3}$ (TNM and 4822 ) and on cubes of $7 \times 7 \times 7 \mathrm{~mm}^{3}$ (IRIS). The samples were ground to 1200 grit using $\mathrm{SiC}$ paper, ultrasonically cleaned with ethanol, rinsed with distilled water and dried in air at RT prior to further studies. Subsequently, a fluorine-containing organic compound based on $\left(\mathrm{C}_{2} \mathrm{~F}_{4}\right)_{\mathrm{n}}$ which was sprayed in a homogeneous manner over the whole surface of the specimens at RT. The samples were sprayed on all sides and dried overnight in a fume hood. The mass change due to fluorine application was measured by weighing the specimens. The amount of the F-containing compound deposited per square centimeter was comparable for all examined samples [27]. All not fluorinated and fluorinated samples were isothermally exposed at $900^{\circ} \mathrm{C}$ in dry synthetic air for $120 \mathrm{~h}$. The mass gain was measured by thermogravimetric analysis (TGA). More specifically, the specimens were connected to a balance and heated up to $900^{\circ} \mathrm{C}$ under a steady stream of dry Ar. After the temperature was reached, the gas was switched to dry synthetic air and the TGA measurement was started. After the end of the envisaged testing period, the furnace was switched off and the specimens were slowly cooled to RT within the furnace (FC) under dry air.

Thermocyclic exposure tests were performed by exposing untreated and F-treated specimens in a furnace at $900^{\circ} \mathrm{C}$ for $24 \mathrm{~h}$ in laboratory air, cooling to RT within 15 min outside of the furnace, weighting with a balance having an accuracy of less than $0.01 \mathrm{mg}$, and finally putting them back 
into the furnace after one hour. In total 25 total test cycles were performed on each alloy variant. Post experimental investigations including the examination of the surface with a Leica magnifier, a Philips XL 40 scanning electron microscope (SEM) coupled with an EDAX energy dispersive X-ray spectroscopy (EDX) and employing a Bruker D8 Advance X-Ray diffractometer (XRD). After surface analysis, all exposed samples were sputtered with gold and galvanically plated with Ni prior to the preparation of metallographic cross-sections [28]. This led to a better visibility of the very thin oxide scales grown on the oxidized samples and protected the scales during metallographic preparation. Furthermore, the cross-sections were analyzed with the SEM mentioned above and an electron probe micro analysis (EPMA) JXA-8100 from Jeol.

\section{Results}

\subsection{Microstructure}

The microstructures of the investigated alloys differ from each other. The following images (Figs. 1a-c) show SEM micrographs taken in back-scattered electron (BSE) mode of the initial material states. The TNM alloy reveals a multi-phase structure with $\alpha_{2} / \gamma$-lamellar grains and globular $\gamma$-grains and $\beta_{\mathrm{o}}$-phase at the colony boundaries (Fig. 1a). The $\beta_{\mathrm{o}}$-phase appears bright, the $\alpha_{2}$-phase grey and the $\gamma$-phase dark grey. The 4822 alloy reveals a two-phase structure with predominantly large lamellar $\alpha_{2} / \gamma$-grains (Fig. 1b). The IRIS alloy, see Fig. 1c, exhibits also a nearly lamellar microstructure with $\gamma$ grains and bright small $\mathrm{W}$-enriched $\beta_{\mathrm{o}}$-precipitates, also occurring within the lamellar colonies. However, the grain size within the IRIS alloy is smaller.
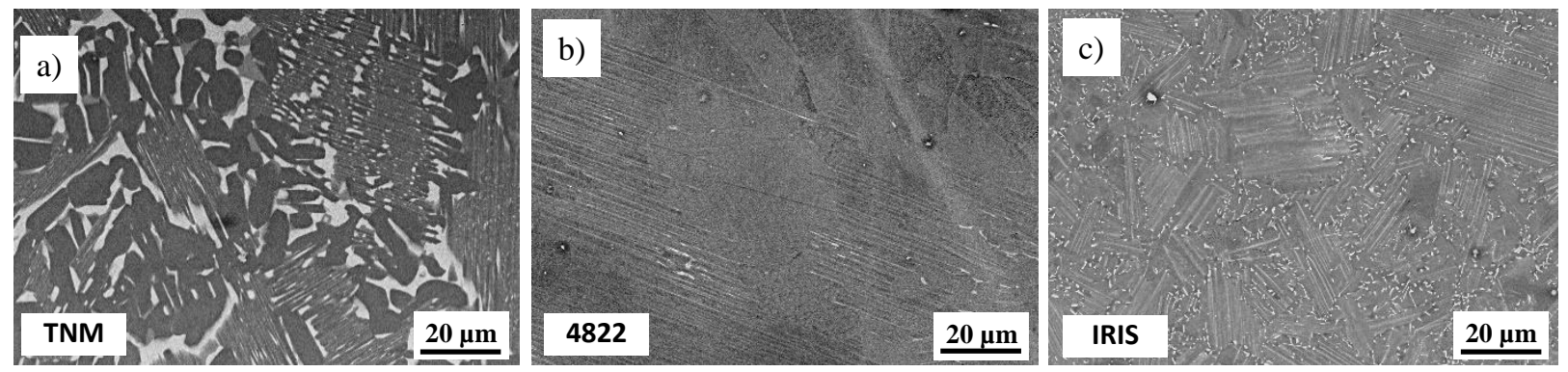

Figure 1: Microstructure of the investigated alloys: a) TNM, b) 4822 and c) IRIS. SEM images taken in BSE mode. Here, the $\gamma$-TiAl phase appears dark, whereas $\alpha_{2}-\mathrm{Ti}_{3} \mathrm{Al}$ and $\beta_{\mathrm{o}}$-TiAl show a grey and white contrast, respectively.

\subsection{Mass change behavior}

The thermogravimetric mass change curves of the untreated alloys during isothermal exposure at $900^{\circ} \mathrm{C}$ for $120 \mathrm{~h}$ in dry synthetic air are presented in Fig. 2. The mass change behavior of the three tested materials during isothermal exposure is similar showing a steady mass gain throughout the exposure (Fig. 2a). The mass gain curves of TNM and 4822 are almost equal while the mass gain for the IRIS alloy is lower over the whole time of exposure. The mass changes of the materials follow the parabolic kinetics. Therefore, the final average mass gain values and $\mathrm{k}_{\mathrm{p}}$ are listed in Table 1. The fluorine treatment reduces the oxidation kinetics for all three tested materials, as shown in Fig. 2b. The mass gain of all fluorine treated samples stays below $1 \mathrm{mg} / \mathrm{cm}^{2}$. The mass gain of the fluorinated TNM sample is slightly higher than that of the 
other two materials. For all specimens in the untreated as well as F-treated condition, no signs of spallation, i.e. mass losses, are visible during isothermal exposure at $900^{\circ} \mathrm{C}$. In this case, too, the final mass gain and $\mathrm{k}_{\mathrm{p}}$ values are listed in Table 1 .

The mass change after thermocyclic exposure of the untreated samples is different as shown in

Fig. 3. The untreated TNM sample reveals a mass gain for the first 6 cycles of exposure which is similar to the isothermal test but after that sudden and abrupt mass losses are recorded which are caused by spallation of larger parts of the oxide scale. Such spallation occurs only during cooling to RT. In comparison, the untreated 4822 sample also exhibits an increase in mass for the first day of about $1.5 \mathrm{mg} / \mathrm{cm}^{2}$, followed by slight mass gains during the next cycles and then by mass loss after seven days of exposure with some minor spallation. After about 10 days the mass loss of small parts of the oxide scale by spallation overcomes the mass gain by oxidation leading to a final mass change of about $-1 \mathrm{mg} / \mathrm{cm}^{2}$ after 25 cycles. The untreated IRIS alloy does not show any spallation and exhibits the lowest mass gain of the three untreated materials, which is steady with a final mass gain of about $2 \mathrm{mg} / \mathrm{cm}^{2}$ after 25 cycles.

In contrast, the F-treated samples of all three alloys reveal a steady and very low mass gain. All three final mass gains are below $1 \mathrm{mg} / \mathrm{cm}^{2}$ after 25 cycles. This indicates the benefit of the fluorine effect for all tested alloys, independent of the chemical composition, the microstructure of the base material as well as the exposure conditions, i.e. isothermal or thermocyclic.

a)

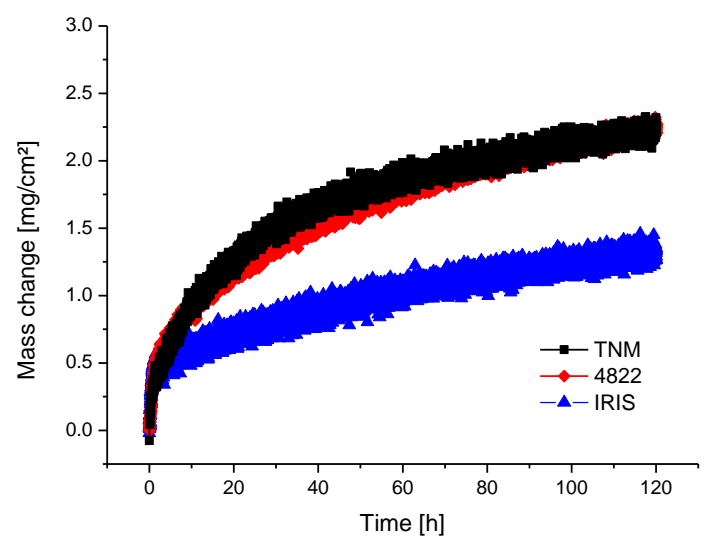

b)

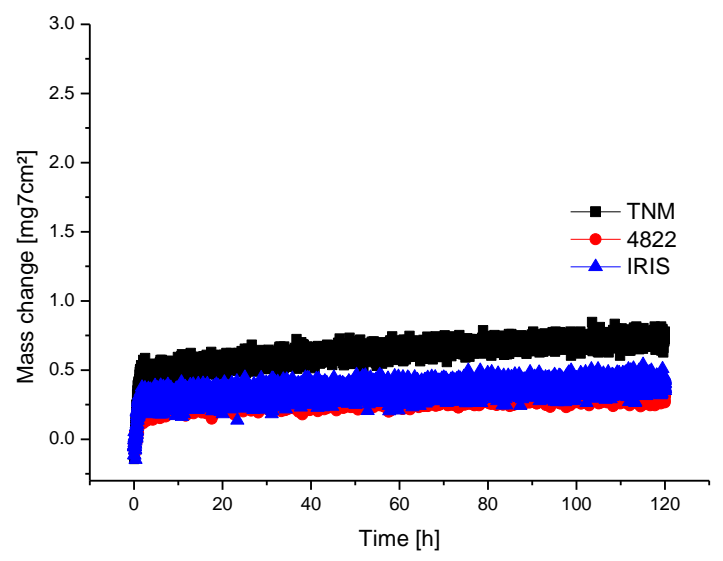

Figure 2a, b: TGA curves obtained during isothermal exposure at $900^{\circ} \mathrm{C}$ in dry synthetic air for $120 \mathrm{~h}$ for the untreated material variants (a) and F-treated material variants (b).

Table 1: Final mass gain and $\mathrm{k}_{\mathrm{p}}$ values of the isothermally $\left(900^{\circ} \mathrm{C}\right.$, dry synthetic air, $\left.120 \mathrm{~h}\right)$ exposed specimens in the untreated and fluorinated $(+\mathrm{F})$ condition.

\begin{tabular}{|l|c|c|c|c|c|c|}
\hline Sample & TNM & TNM+F & 4822 & $4822+\mathrm{F}$ & IRIS & IRIS+F \\
\hline$\Delta \mathrm{m}\left[\mathrm{mg} / \mathrm{cm}^{2}\right]$ & 2.3 & 0.7 & 2.3 & 0.3 & 1.4 & 0.4 \\
\hline $\mathrm{k}_{\mathrm{p}}\left[\mathrm{mg}^{2} / \mathrm{cm}^{4} \mathrm{~s}\right]$ & $1.22 \times 10^{-5}$ & $1.13 \times 10^{-6}$ & $1.22 \times 10^{-5}$ & $2.08 \times 10^{-7}$ & $4.54 \times 10^{-6}$ & $3.70 \times 10^{-7}$ \\
\hline
\end{tabular}




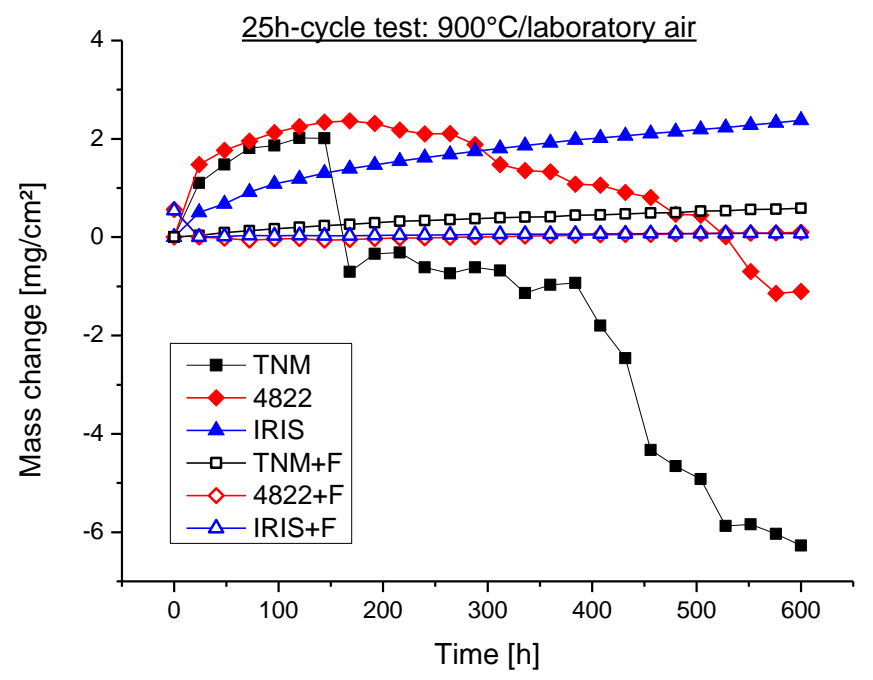

Figure 3: Mass change curves of the three untreated and F-treated $\gamma$-TiAl-based alloys during thermocyclic exposure at $900^{\circ} \mathrm{C}$ in laboratory air for $600 \mathrm{~h}$. Here, so-called $25 \mathrm{~h}$ cycle tests, see text, were conducted.

\subsection{Surface analysis}

Optical analysis of the untreated specimens confirms different behavior of the materials during thermocyclic exposure (Fig. 4). The TNM alloy exhibits more spallation (Fig. 4a), which is in accordance to the mass change data (Fig. 3), when compared to the 4822 material (Fig. 4b). On the TNM sample surface residues of the oxide scale after the last cycle are still present at the outer areas of the specimen, while for the 4822 sample the oxide scale spalled off at the edges and corners. The IRIS alloy shows the lowest spallation rate. Only a small spalled area is found at one edge (Fig. 4c). These results correlate with the mass change data shown in Fig. 3. All fluorine treated samples look similar, hence, only one representative image is shown in Fig. 4d. They appear grey without any signs of spallation. 

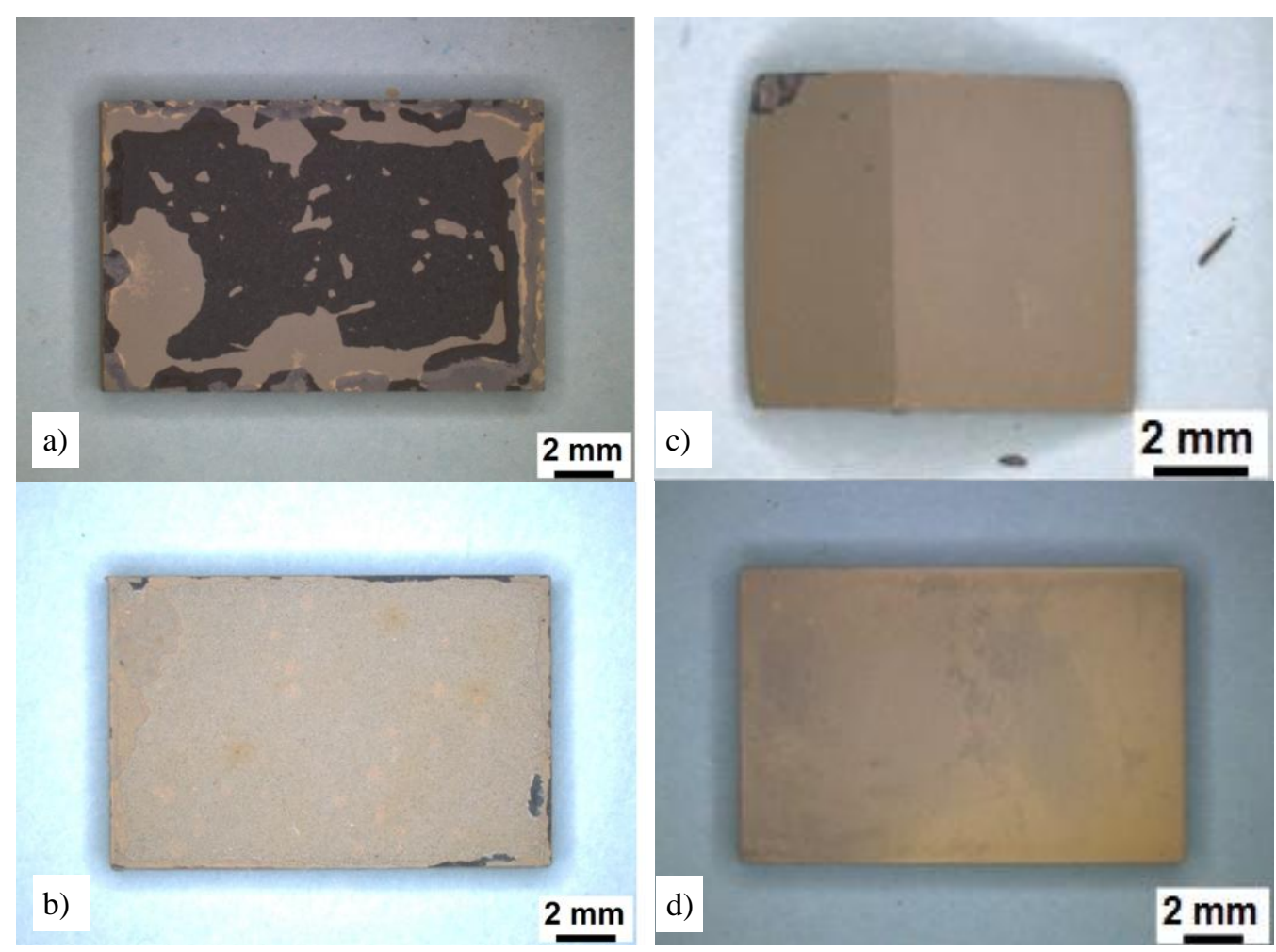

b)

$2 \mathrm{~mm}$

$2 \mathrm{~mm}$

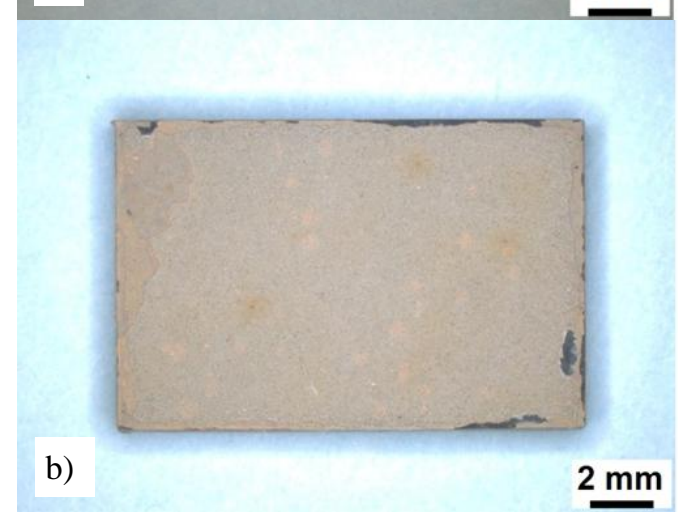

Figure 4a-d: Magnified images of the untreated materials TNM (a), 4822 (b), IRIS (c) and the fluorine treated TNM sample (d) after thermocyclic exposure at $900^{\circ} \mathrm{C}$ in laboratory air for 600 h.

Taking a closer look at higher magnification of the oxide scale residues by means of SEM, similar structures of coarse crystals on all untreated alloy variants are detected. Hence, only one image of the untreated TNM sample is exemplarily presented in Fig. 5a. The image was taken in secondary electron (SE) mode to obtain a better impression of the surface topography. The crystals consist of $\mathrm{TiO}_{2}$, which was proven by $\mathrm{EDX}$ (see inset). The measurements were performed with energies from $10 \mathrm{keV}$ up to $20 \mathrm{keV}$ so that also deeper zones of the oxide scale were measured, but the peak ratio always stays the same. It should be kept in mind, that no $\mathrm{Nb}, \mathrm{Cr}$, Mo or $\mathrm{W}$ from the base material was detected, i.e. the oxide scales on the untreated materials are thicker than the penetration depth, even at $20 \mathrm{keV}$ (Tab. 2). For lack of space, no image and measurement of a spalled area are shown.

The fluorine treated samples totally differ in their surface quality. They all also look similar despite their different starting microstructure and chemical composition. Thus, exemplary the corresponding image of the F-treated TNM sample is presented. No spallation can be observed even after thermocyclic exposure for $600 \mathrm{~h}$, i.e. $25 \mathrm{~h}$ cycles, at $900^{\circ} \mathrm{C}$ in air. The surfaces are smooth and homogeneous, see Fig. 5b, and no coarse oxide crystals are observed. The EDX analysis, which was performed within the same intensity range as the untreated samples $(10-20 \mathrm{keV})$, reveals the peaks of $\mathrm{Nb}$ and $\mathrm{Mo}$ so that the substrate was detected underneath the thin oxide scale, too (Tab. 2). XRD analyses of the exposed samples reveal similar results. Hence, as an example, only the patterns of the exposed TNM samples are presented (Fig. 6). The main peaks arise from the oxides $\mathrm{TiO}_{2}$ and $\mathrm{Al}_{2} \mathrm{O}_{3}$ in addition to the substrate phases, $\gamma-\mathrm{TiAl}, \alpha_{2}-\mathrm{Ti}_{3} \mathrm{Al}$ and $\beta_{0^{-}}$ TiAl. For the fluorinated sample the peaks from the substrate have the highest intensity indicat- 
ing a thinner oxide layer while for the untreated sample the peak with the highest intensity is correlated to $\mathrm{TiO}_{2}$.
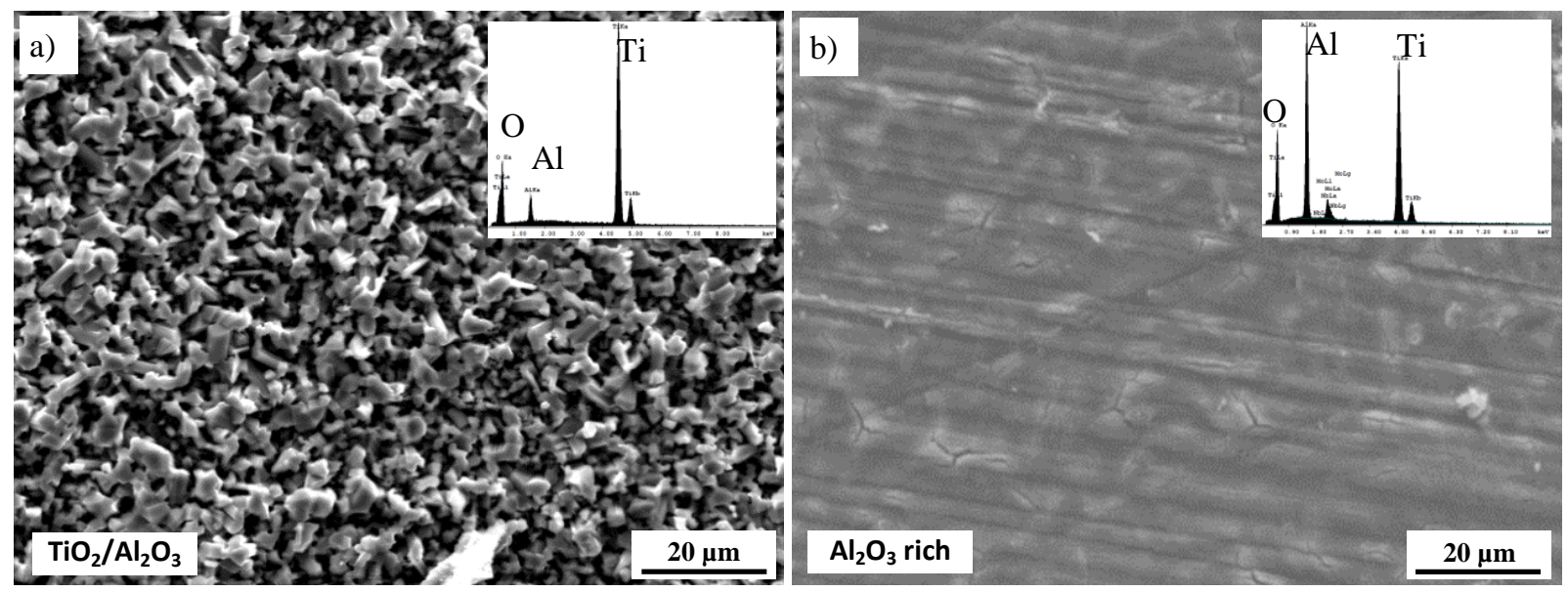

Figure 5: SEM/SE images and embedded EDX spectra $(20 \mathrm{keV})$ of the surface of the untreated a) and F-treated b) TNM samples after thermocyclic exposure at $900^{\circ} \mathrm{C}$ under laboratory air for 600 h (25 h-cycle tests).

Table 2: Elemental quantification (at.\%) of the EDX spectra shown in Fig. 5

\begin{tabular}{|c|c|c|}
\hline Element & Untreated TNM & TNM + F \\
\hline $\mathrm{Al}$ & 9.4 & 19.3 \\
\hline $\mathrm{Ti}$ & 24.7 & 18.3 \\
\hline $\mathrm{O}$ & 65.9 & 60.8 \\
\hline $\mathrm{Nb}$ & - & 1.2 \\
\hline $\mathrm{Mo}$ & - & 0.4 \\
\hline
\end{tabular}




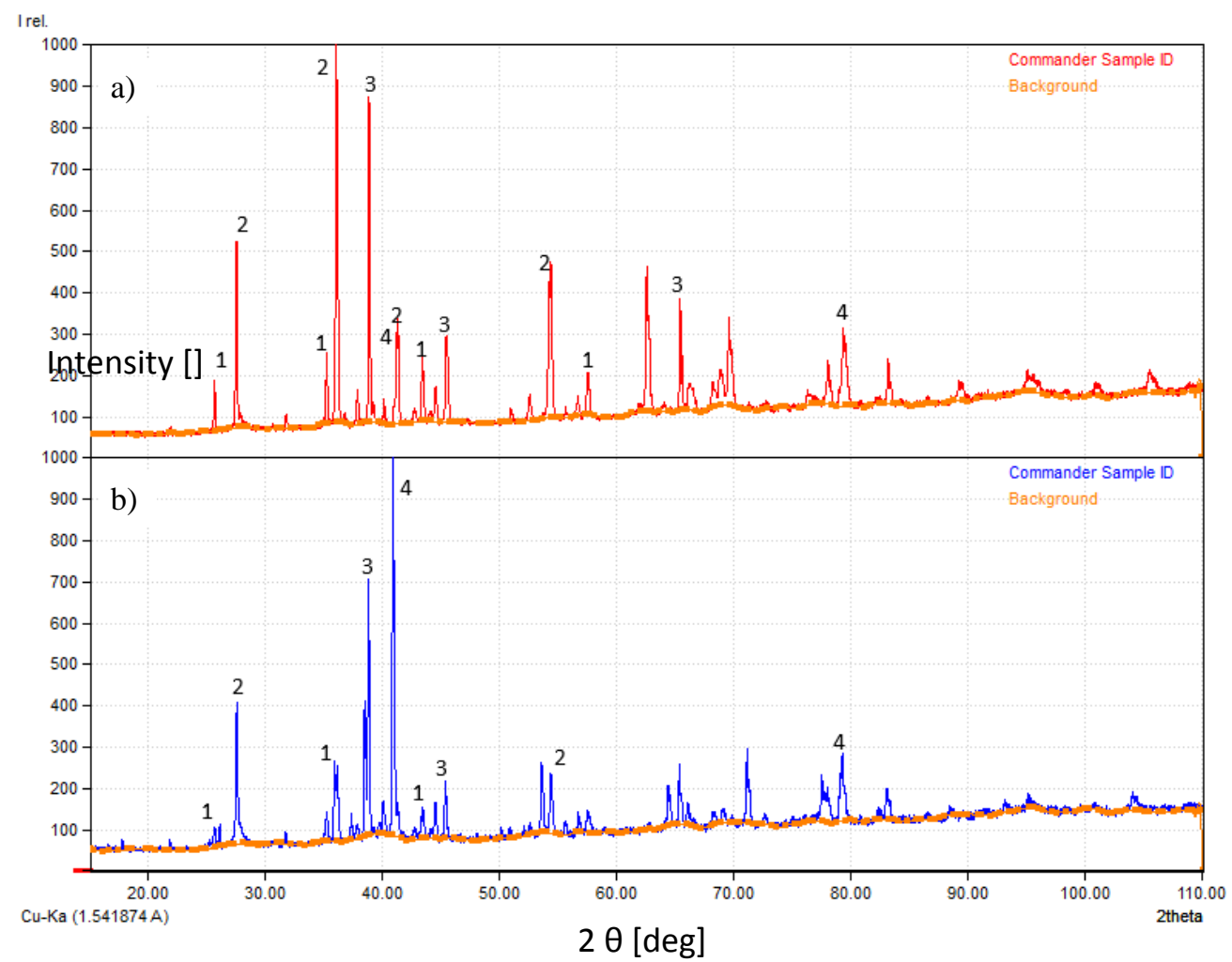

Figure 6a, b: XRD patterns of the surface of the exposed TNM samples a) without treatment and b) with fluorine, both after $120 \mathrm{~h}$ of exposure at $900^{\circ} \mathrm{C}$ in dry synthetic air $\left(1=\mathrm{Al}_{2} \mathrm{O}_{3} / 2=\mathrm{TiO}_{2} /\right.$ $\left.3=\gamma-\mathrm{TiAl} / 4=\alpha_{2}-\mathrm{Ti}_{3} \mathrm{Al}\right)$

\subsection{Oxide scale analysis}

Metallographic cross-sections of the specimens after exposure were prepared in order to investigate the scales that have formed during exposure. LOM investigations provide a first impression of the formed oxide scales, but do not allow a closer look on the composition and morphology of the scales formed. Therefore, no LOM images are presented.

Detailed insight on the composition of the oxide scales is given by SEM investigations and further understanding is gained by additional EPMA measurements. The following SEM images in BSE mode allow to distinguish phases containing light or heavy alloying elements. Here, phases with more dense alloying elements show a brighter contrast. The remaining parts of the mixed scale which stayed attached on the surface of the untreated TNM alloy are about $10 \mu \mathrm{m}$ thick (Fig. 7a). Outer coarse rutile crystals, which have been identified by EDX, are followed by a darker alumina enriched zone. This thin Al-rich layer is clearly visible. This is the case for all three alloys (Figs. 8-10). Underneath this zone a porous mixed oxide scale can be found. This mixed scale forms the thickest part of the total oxide scale and contains some $\mathrm{Nb}$ (Fig. 8f). However, no $\mathrm{Nb}$ is found within the Al-rich layer. At the interface oxide/substrate some enrichment of $\mathrm{Nb}$ (bright contrast) and $\mathrm{N}$ is detected. This scale morphology is characteristic for $\gamma$-TiAl based alloys oxidized in air. The elemental distributions reveal the formation of a mixed $\mathrm{TiO}_{2} / \mathrm{Al}_{2} \mathrm{O}_{3}$ scale along with a thin nitride layer (Fig. 8e). The results for the untreated 4822 alloy are similar (Fig. 7b). The oxide scale morphology is comparable, but the nitride layer is more pronounced (Fig. 9e). At the interface towards the substrate an almost continuous nitride layer 
can be found on both samples. Additionally, $\mathrm{Nb}$ enrichment at the interface is visible. The elemental intensities in the EPMA elemental distributions are the same for all samples so that a comparison of the prevailing amounts can be made. The scale on the untreated IRIS alloy appears different. The scale is thinner (Fig. 7c). The alumina enriched zone is more compact and the mixed scale underneath is also thinner. Additionally, less outer rutile crystals are visible. Some $\mathrm{W}$ is found in the mixed scale but not in the alumina rich layer (Fig. 10f). The W distribution is similar to that of $\mathrm{Nb}$. In the IRIS alloy some areas reveal local attack into the depth of the material. This attack reaches about $15 \mu \mathrm{m}$ below the oxide scale into the material. EPMA again reveals a continuous nitride layer underneath the mixed oxide scale at the interface towards the substrate (Fig. 10).

As a conclusion, qualitatively similar oxide scales are observed in all three F-untreated alloys, with the successive observation of rutile, alumina and mixed oxide layers. In all cases, the oxides are separated from the alloy by a thin nitride layer. The differences are mainly due to the thickness of the mixed oxide scale which is thicker in case of the TNM and 4822 alloys, to some spallation in these two alloys and to the presence of a local attack in the IRIS sample which is crossing the oxide layer. Interestingly, similar repartitions are measured for $\mathrm{Nb}$ and $\mathrm{W}$, indicating the same oxidation mechanisms.
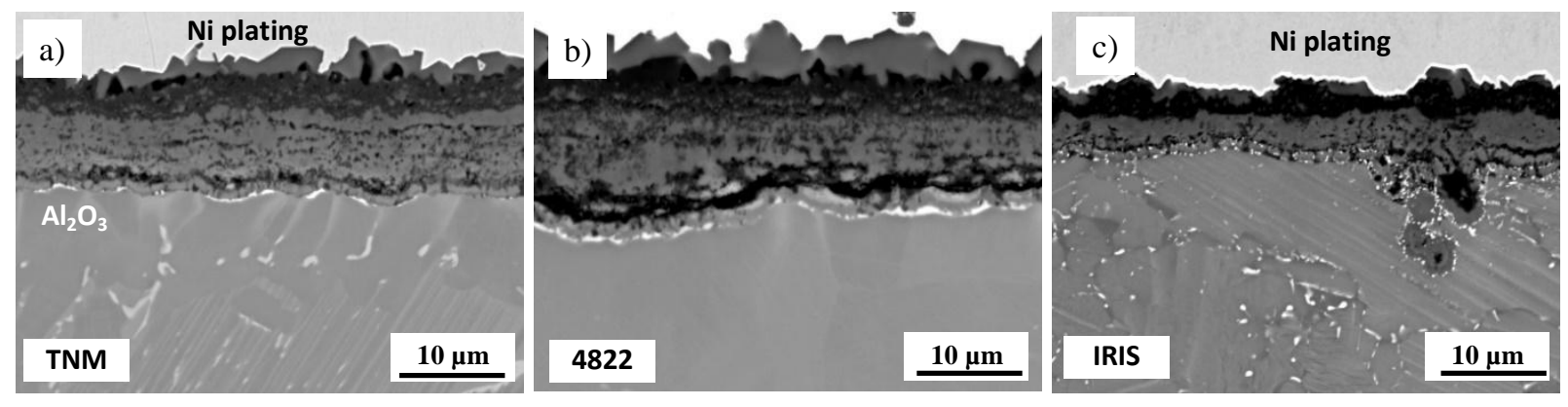

Figure 7: SEM/BSE images of the mixed oxide scales on the a) untreated TNM sample, b) untreated 4822 sample and c) untreated IRIS sample after isothermal exposure at $900^{\circ} \mathrm{C}$ in laboratory air for $120 \mathrm{~h}$. 


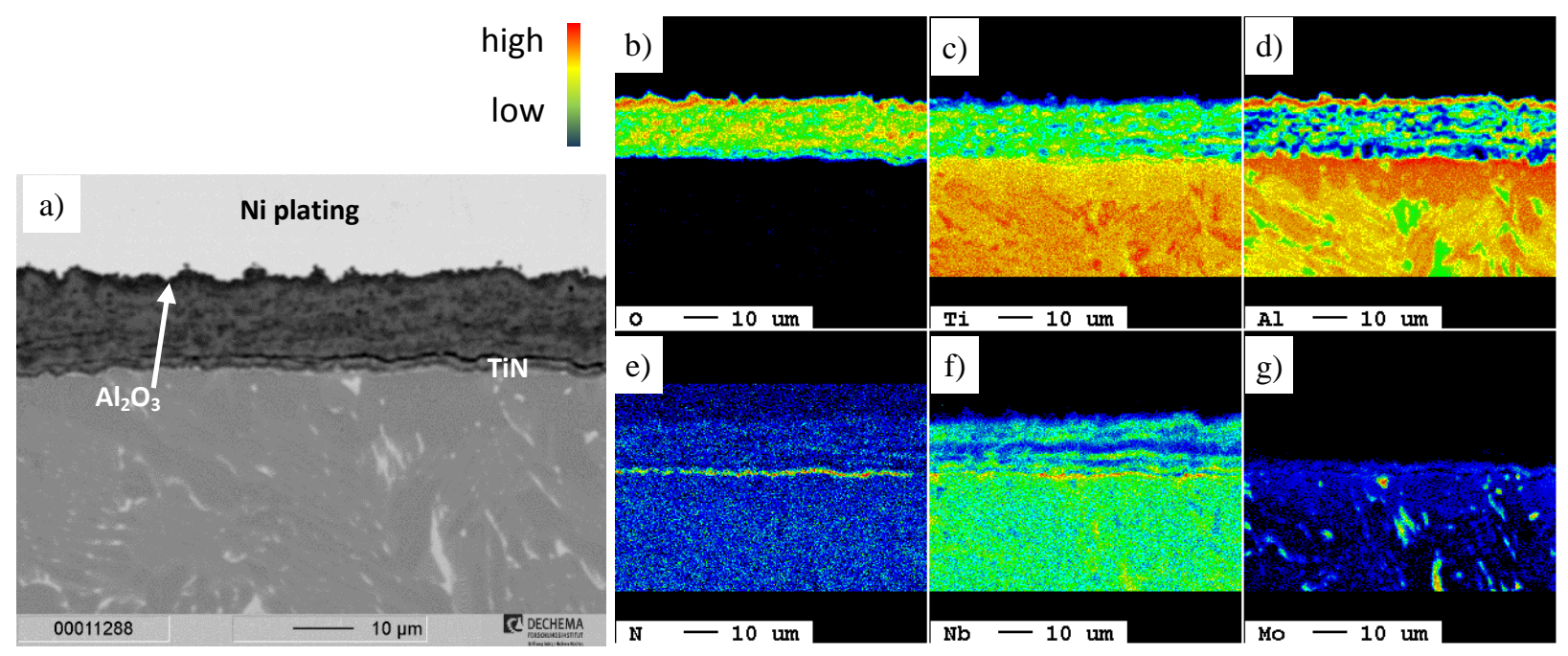

Figure 8: a) SEM/BSE image and corresponding EPMA elemental distributions of b) O, c) Ti, d) $\mathrm{Al}, \mathrm{e}$ ) $\mathrm{N}, \mathrm{f}) \mathrm{Nb}$, and $\mathrm{g}$ ) Mo of the mixed oxide scale of the untreated TNM sample after isothermal exposure at $900^{\circ} \mathrm{C}$ in laboratory air for $120 \mathrm{~h}$.

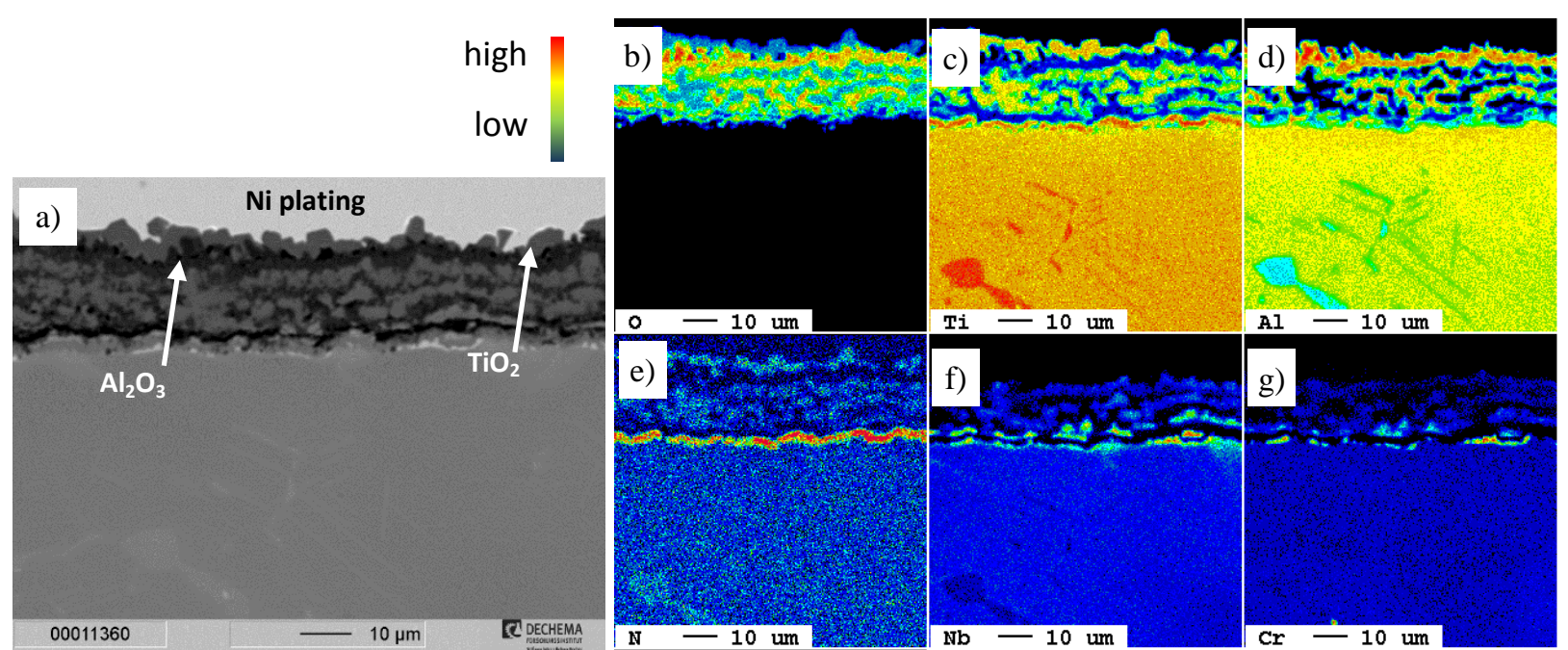

Figure 9: a) SEM/BSE image and corresponding EPMA elemental distributions of b) O, c) Ti, d) $\mathrm{Al}$, e) $\mathrm{N}, \mathrm{f}$ ) $\mathrm{Nb}$, and g) $\mathrm{Cr}$ of the mixed oxide scale of untreated 4822 sample after isothermal exposure at $900^{\circ} \mathrm{C}$ in laboratory air for $120 \mathrm{~h}$. 


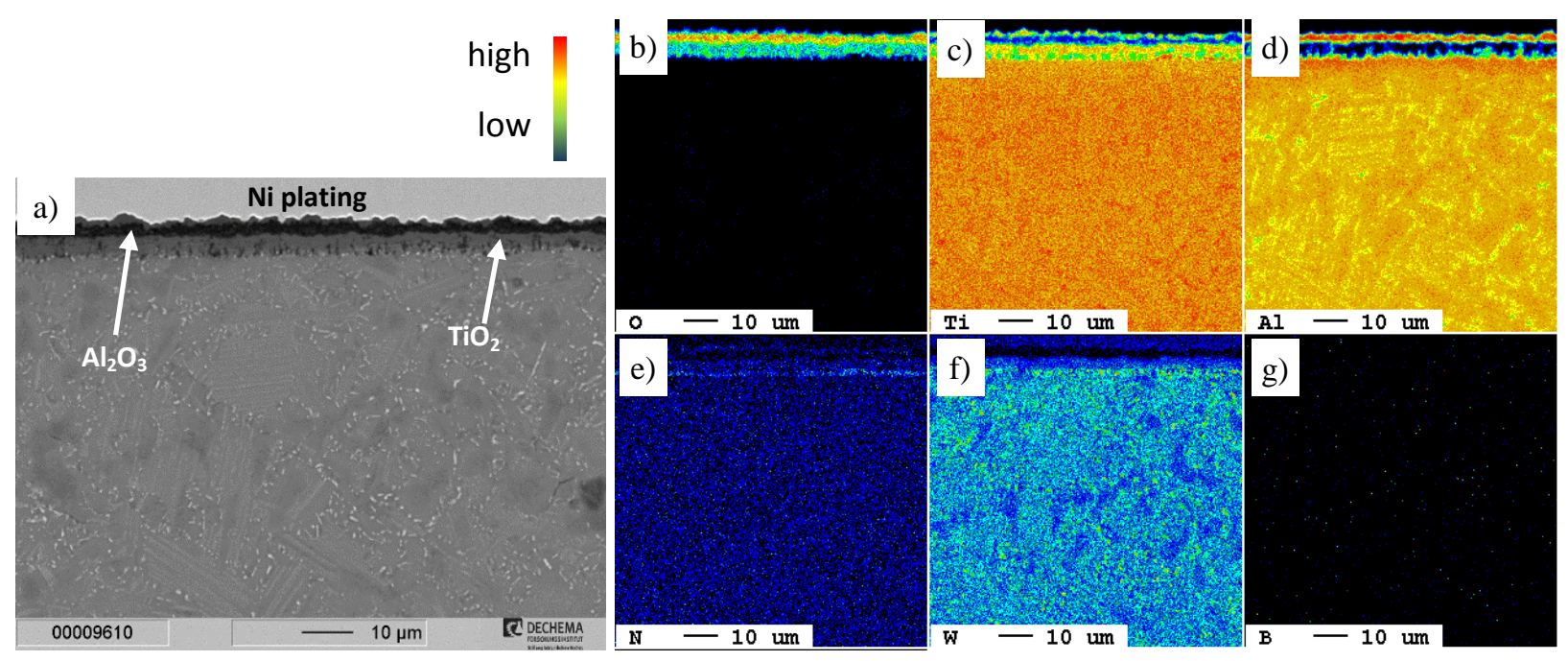

Figure 10: a) SEM/BSE image and corresponding EPMA elemental distributions of b) O, c) Ti, d) $\mathrm{Al}$, e) $\mathrm{N}, \mathrm{f}$ ) $\mathrm{W}$, and g) B of the mixed oxide scale of untreated IRIS sample after isothermal exposure at $900^{\circ} \mathrm{C}$ in laboratory air for $120 \mathrm{~h}$.

Thermocyclic exposure for $600 \mathrm{~h}$, i.e. $25 \mathrm{~h}$ cycles, leads to pronounced spallation on the untreated TNM and 4822 samples (Figs. 4a, b). This was not the case for the IRIS alloy (Fig. 4c). The oxide scale morphologies on the three materials are mostly the same as after isothermal exposure, but the scales are thicker (Figs. 11a-c) which can be explained by the longer exposure time, i.e. $600 \mathrm{~h}$ vs. $120 \mathrm{~h}$. As can be seen in Fig. 11a spallation does not lead to the total exfoliation of the oxide scale. Some oxides/nitrides remain on the surface as a thin layer. Here the access of the atmosphere towards the substrate is much easier when compared to areas where a thick scale has remained. Consequently, at these spots an accelerated attack can take place. The scales are porous and crackly. At the interface towards the substrate enrichments of the heavy additional elements, i. e. $\mathrm{Cr}, \mathrm{Nb}$ or $\mathrm{W}$, can be seen in the SEM/BSE images where phases containing heavy elements appear brighter than those bearing light elements. The remained scale on the 4822 sample looks similar but is thicker (Fig. 11b) than the scale on the IRIS sample (Fig. 11c) which exhibits the thinnest one of the three alloys. The dark alumina layer within the scale is broad and compact, but at the interface towards the substrate there are cracks and pores.

Nevertheless, it has to be mentioned, that in some spots an accelerated attack was observed on the untreated IRIS sample, which was not the case for the other two materials. Such spots were found on several areas of the specimen. A closer look on such a spot reveals a thick and porous mixed oxide underneath the outer alumina (Fig. 12a) and a fine scale at the interface towards the substrate which is enriched with very bright particles, see Fig. 12b. EDX analysis of these spots disclose a high amount of nitride formation adjacent to the oxides based of $\mathrm{Al}$ and $\mathrm{Ti}$ within this very thick mixed scale (Fig. 12d) and a roughly $2 \mu \mathrm{m}$ thick dense nitride layer at the interface towards the substrate (Fig. 12e). The total thickness of the scale in such a spot can reach more than $100 \mu \mathrm{m}$ in depth (Fig. 12c). 

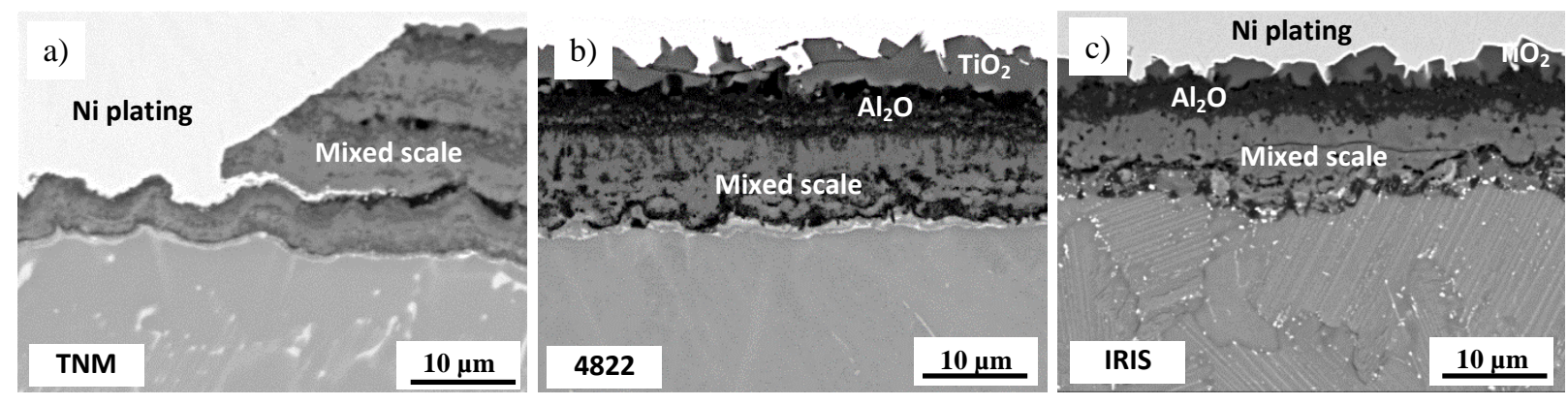

Figure 11: SEM/BSE images of the mixed oxide scales on the untreated alloys after thermocyclic exposure for $600 \mathrm{~h}$ at $900^{\circ} \mathrm{C}$ in laboratory air: a) TNM, b) 4822 and c) IRIS.

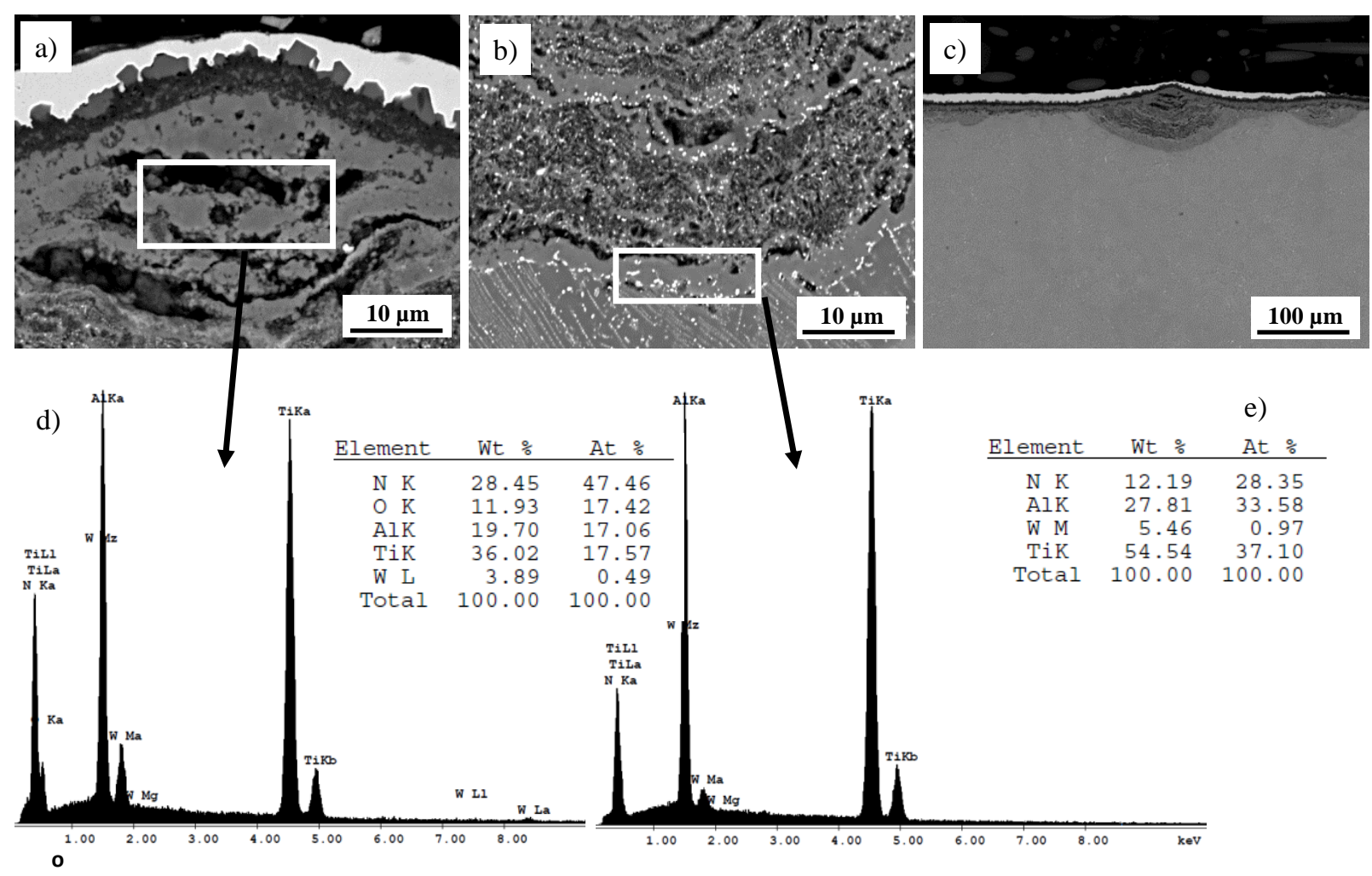

Figure 12: SEM/BSE images of a) an area with accelerated attack and b) corresponding EDX spectrum; c) interface towards the substrate underneath the zone with accelerated attack, d) corresponding EDX spectrum, and e) overview image of the untreated IRIS sample after $25 \mathrm{~h}$ cycles, i.e. $600 \mathrm{~h}$ exposure at $900^{\circ} \mathrm{C}$ in laboratory air.

Fluorination totally changes the oxidation behavior of all three alloy variants. Instead of a mixed oxide scale, a thin alumina rich layer was formed after high temperature exposure. The observed behavior shows that in case of the investigated alloys the F-process is independent of chemical composition, initial microstructure and the processing history of the alloys as well as the exposure conditions (isothermal vs. thermocyclic or dry synthetic air vs. laboratory air). 
In the following section only images of the fluorinated samples after thermocyclic exposure at $900^{\circ} \mathrm{C}$ for $600 \mathrm{~h}$ in laboratory air will be shown. Minor differences between the materials become visible by means of SEM examination. The BSE image of the F-treated TNM sample shows a slightly thicker oxide (roughly $4 \mu \mathrm{m}$ ) when compared to the two other alloys, with some pores at the oxide/metal interface (Fig. 13a). At the interface also a continuous brighter zone is visible. This is caused by Al-depletion via alumina formation. This zone is more pronounced on the exposed and treated 4822 sample (Fig. 13b). Here, the alumina layer is smooth and thinner (< $2 \mu \mathrm{m}$ ) when compared to the TNM sample and appears more compact. Again, the scale on the Ftreated IRIS specimen looks different, i.e., the scale is not so even, see Fig. 13c. The surface of the alumina layer is rough and the subsurface zone of the substrate is enriched in $\mathrm{W}$, while $\mathrm{Al}$ is depleted. The EPMA results prove these findings. On top of the alumina layer some rutile crystals can be found on the fluorinated TNM sample (Fig. 14) and depletion of Al is obvious. Some $\mathrm{Nb}$ enrichment underneath the oxide scale is visible, too. The signals of Mo and B are too low to make such a similar conclusion. For the 4822 alloy the alumina layer is thinner compared to the TNM sample (Fig. 15). Also, the Al depleted zone appears thinner and no enrichments of $\mathrm{Nb}$ and $\mathrm{Cr}$ are detectable. The scales on the F-treated IRIS specimen are different again (Fig. 16). The alumina layer is thin and homogeneous, but the Al depleted zone is thicker. Additionally, several $\mathrm{W}$-enriched spots are found in the $\mathrm{Al}$ depleted zone.
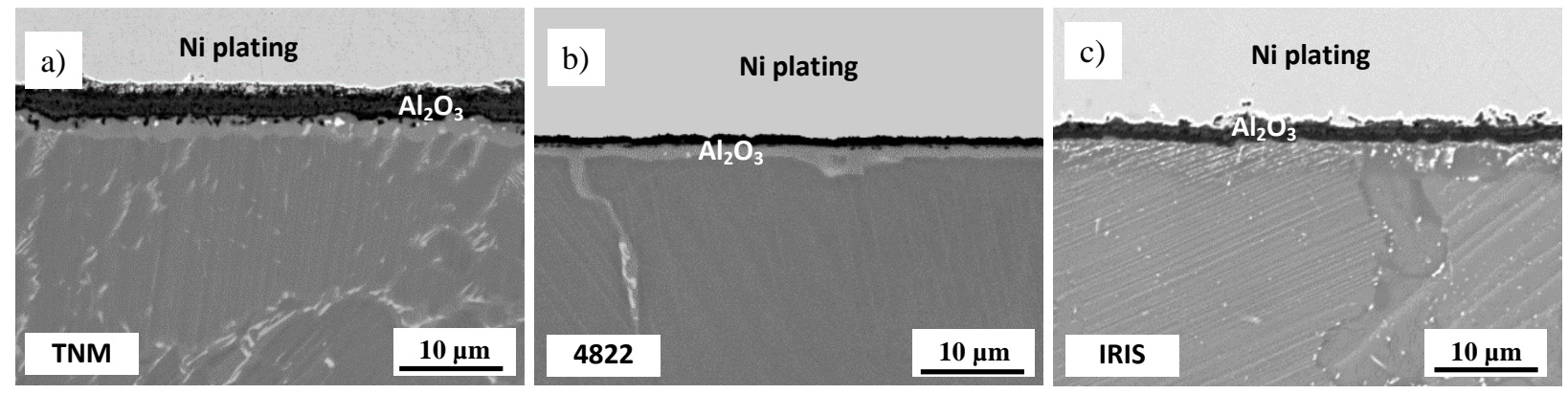

Figure 13: SEM/BSE images of metallographic cross-sections of the F-treated material variants: a) TNM sample, b) 4822 sample and c) IRIS sample after thermocyclic exposure at $900^{\circ} \mathrm{C}$ in laboratory air for $25 \mathrm{~h}$ cycles, i.e. $600 \mathrm{~h}$. 


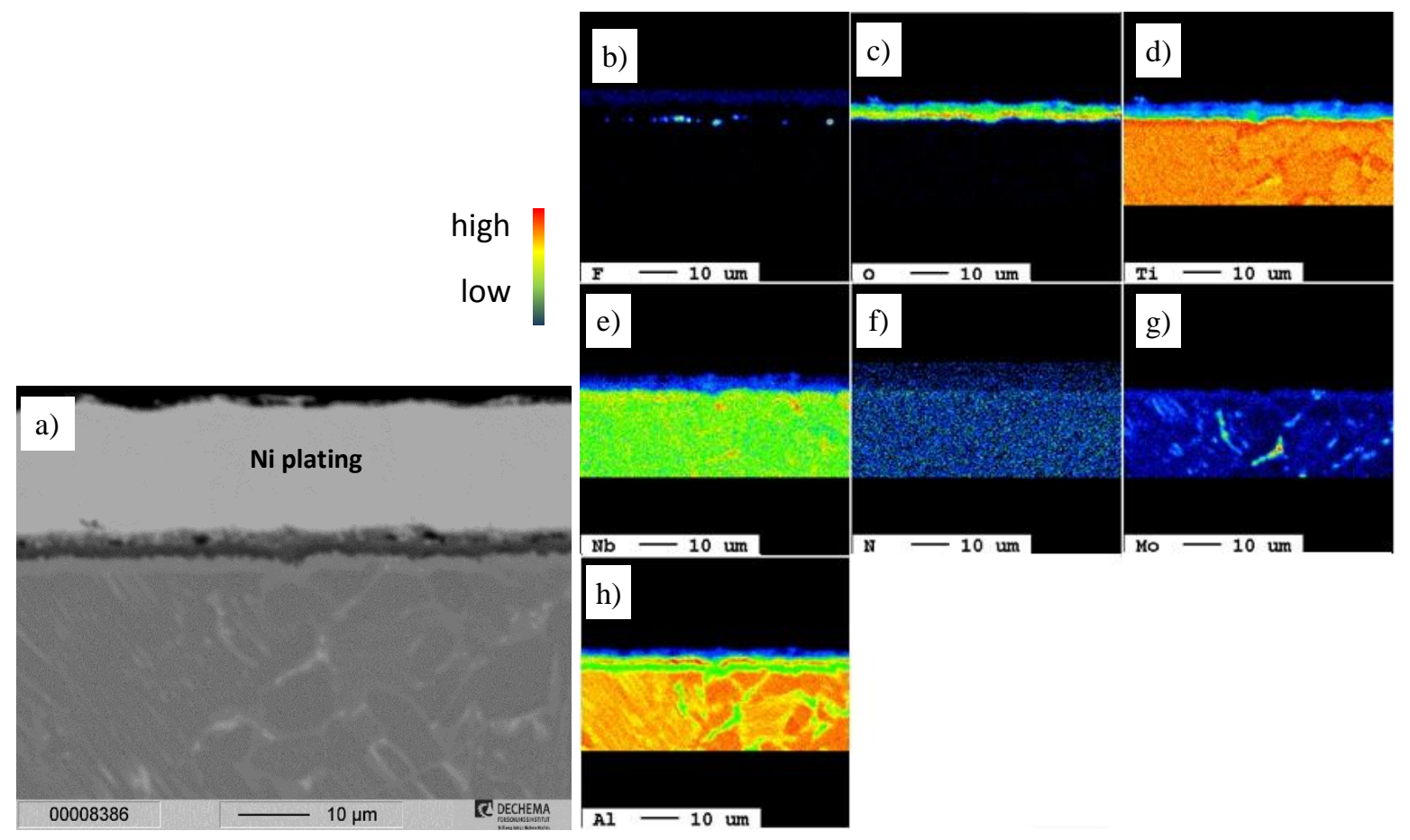

Figure 14: a) SEM/BSE image and corresponding EPMA elemental distributions of b) F, c) O, d) $\mathrm{Ti}$, e) $\mathrm{Nb}, \mathrm{f}$ ) $\mathrm{N}, \mathrm{g}$ ) $\mathrm{Mo}$, and h) $\mathrm{Al}$ of the oxide scale of F-treated TNM sample after thermocyclic exposure at $900^{\circ} \mathrm{C}$ in laboratory air for $600 \mathrm{~h}$.

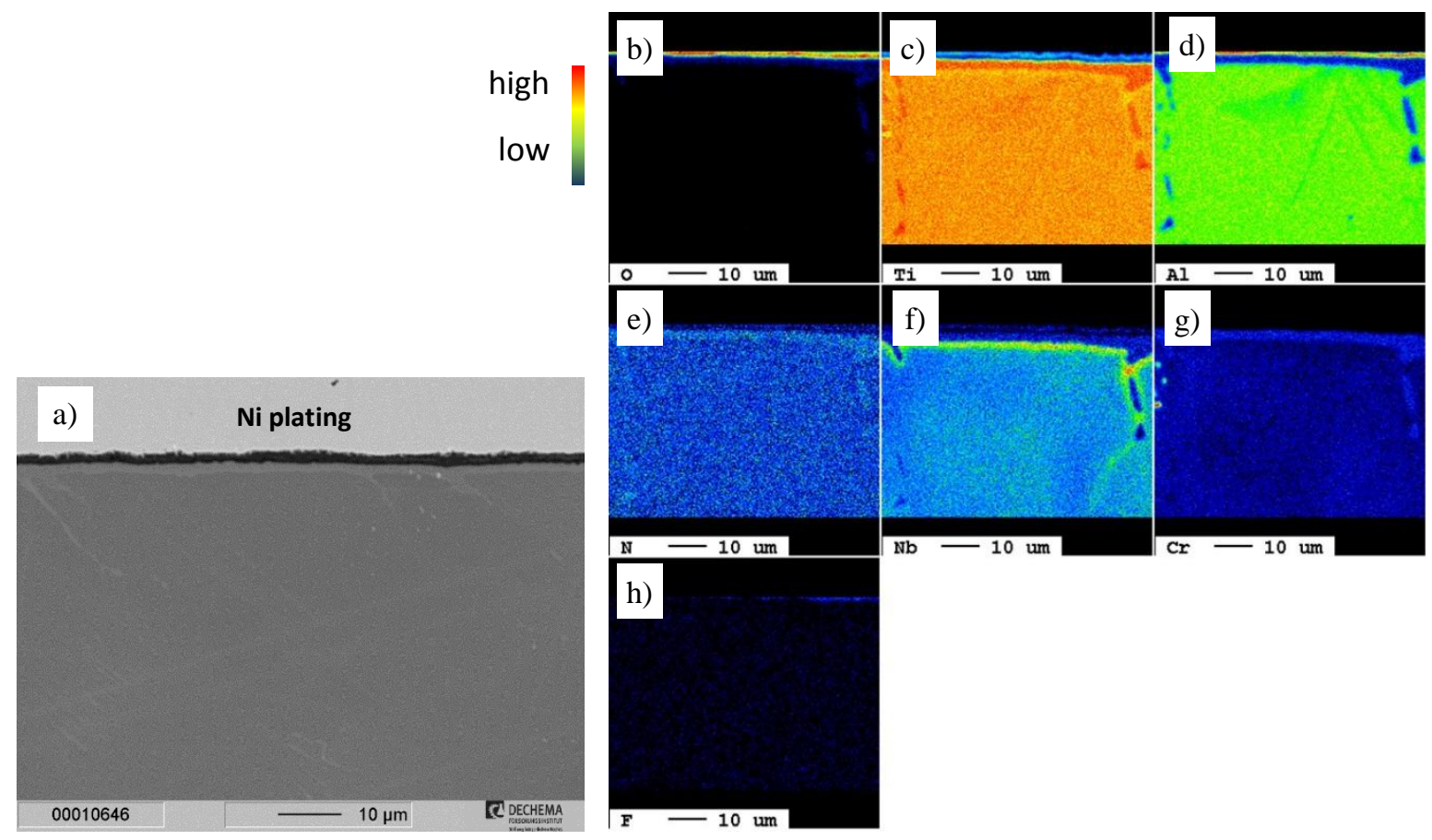

Figure 15: a) SEM/BSE image and corresponding EPMA elemental distributions of b) O, c) Ti, d) $\mathrm{Al}$, e) $\mathrm{N}$, f) $\mathrm{Nb}, \mathrm{g}$ ) $\mathrm{Cr}$, and h) $\mathrm{F}$ of the oxide scale of F-treated 4822 sample after thermocyclic exposure at $900^{\circ} \mathrm{C}$ in laboratory air for $600 \mathrm{~h}$. 


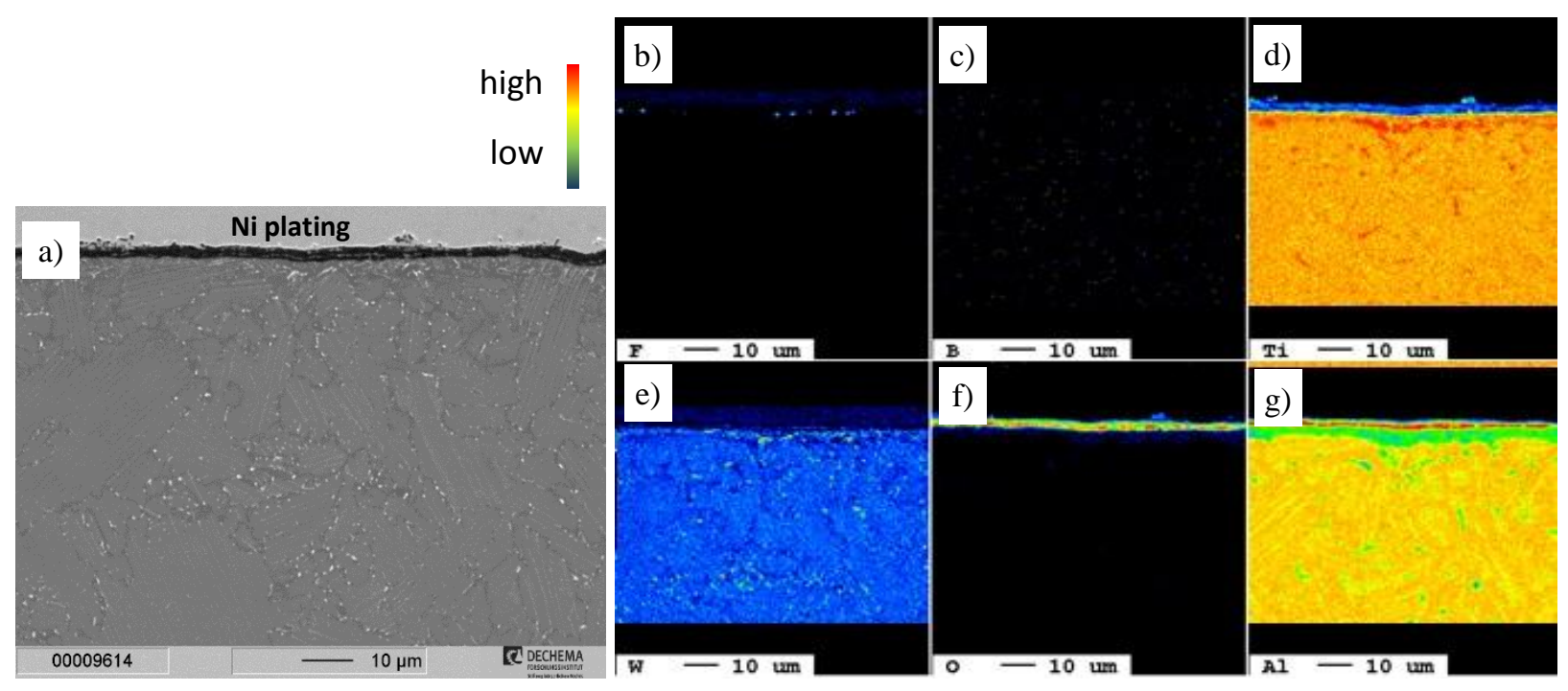

Figure 16: a) SEM/BSE image and corresponding EPMA elemental distributions of b) F, c) B, d) $\mathrm{Ti}, \mathrm{e}) \mathrm{W}, \mathrm{f}) \mathrm{O}$, and g) $\mathrm{Al}$ of the oxide scale of the F-treated IRIS sample after thermocyclic exposure at $900^{\circ} \mathrm{C}$ in laboratory air for $600 \mathrm{~h}$.

\section{Discussion}

The results presented in this paper describe the high temperature oxidation behavior of three engineering $\gamma$-TiAl-based alloys at $900^{\circ} \mathrm{C}$ in air. In the following the influence of the initial microstructure, the chemical composition and the fluorine effect on the oxidation behavior will be discussed.

The TNM alloy has the lowest $\mathrm{Al}$ content (43.5 at.\%) of the examined alloys, but its oxidation behavior is similar to the two other alloy variants, both showing an Al content of 48 at.\%. Furthermore, the TNM alloy contains a significant amount of $\beta_{\mathrm{o}}$-TiAl phase besides $\gamma$-TiAl and $\alpha_{2}-\mathrm{Ti}_{3} \mathrm{Al}$ phase, while the other alloys predominantly consist of $\gamma$ and $\alpha_{2}$. The $\beta$-phase undergoes a phase transition from the disordered high temperature $\beta$-Ti(Al) with $\mathrm{A} 2$ structure towards the ordered $\beta_{\mathrm{o}}$ with B2-structure above service temperature [29]. The globular $\beta_{\mathrm{o}}$-phase in the initial microstructure is located at the boundaries of lamellar $\gamma / \alpha_{2}$-colonies, where also some globular $\gamma$ phase can be found. The two other alloys consist mainly of lamellar $\gamma / \alpha_{2}$-colonies with almost no globular $\gamma$-grains at their boundaries.

In general, the $\mathrm{Al}$ content of the $\alpha_{2}$-phase is lower when compared to the $\gamma$-phase, so that preferential Ti oxide formation is observed during oxidation of this phase, especially if it is present in globular form as reported in [30]. Globular $\beta_{0}$-grains at the surface, however, negatively influence the oxidation behavior. Therefore, the microstructure and, more specifically, the phase distribution affect the oxidation resistance and thus have to be taken into account [31, 32].

Next to the microstructure the alloying elements present have a significant impact, for example, a certain amount of $\mathrm{Nb}$ improves the oxidation resistance of $\gamma$-TiAl-based alloys by several combining mechanisms, see ref. [33]. This is also the case for the TNM alloy which contains 4 at. $\% \mathrm{Nb}$. The alloy forms a slightly thinner and more homogeneous mixed oxide scale when 
compared to the one found on the surface of the untreated 4822 sample with a higher $\mathrm{Al}$ content, but exhibiting a lower $\mathrm{Nb}$ content of 2 at. \%. Both $\mathrm{Nb}$ and Mo are known to be beneficial for the oxidation behavior, while $\mathrm{Cr}$ shows a detrimental effect [34]. However, the negative effect of $\mathrm{Cr}$ within the 4822 alloy is compensated by the higher $\mathrm{Al}$ content along with the addition of $\mathrm{Nb}$, while for the TNM alloy $\mathrm{Nb}$ and Mo determine the overall oxide scale formation. The influence of $\mathrm{W}$ which has also a positive effect on the oxidation behavior [35] in the IRIS alloy is discussed further below.

It is tempting to speculate that the higher spallation rate of the TNM alloy is a consequence of the microstructure which, in contrast to the other alloys, consists of three phases. The phase transformation from the disordered $\beta$ to the ordered $\beta_{\mathrm{o}}$ should be no reason for stresses within the substrate because it happens above $1000^{\circ} \mathrm{C}$ where the material is ductile enough to release such stresses. Due to higher solubilities, the uptake of $\mathrm{O}$ into the phases is higher for the $\alpha_{2}$ - and $\beta_{0^{-}}$ phase when compared to the $\gamma$-phase, which in turn can change their lattice parameters [30]. This happens within the subsurface zone of the material directly underneath the oxide scale. Such O uptake might cause a higher stress level within the TNM alloy compared to the other two alloy variants, especially when globular $\beta_{\mathrm{o}}$-grains are located at the interface with the oxide, explaining the onset of spallation if a certain stress level is reached [10]. The 4822 alloy is also susceptible for spallation, especially during thermocyclic exposure but to a lesser extent when compared to the TNM alloy. The mixed scale consists of $\mathrm{TiO}_{2}, \mathrm{Al}_{2} \mathrm{O}_{3}$ and at the interface towards the substrate TiN which have similar coefficients of thermal expansion (CTE) [33-35]. The CTEs for $\mathrm{TiO}_{2}$ depend on the crystal axis, i.e. 7.14 (parallel to a) and 9.19 (parallel to c). The CTE for $\mathrm{Al}_{2} \mathrm{O}_{3}$ is 8.1 and the one for TiN 9.4 (all multiplied by $10^{-6} \mathrm{~K}$ ). However, these are lower than those of the $\alpha_{2^{-}}$and $\gamma$-phase, neglecting the effects of additional elements [38]. Since the scales on all untreated materials are similar in composition the CTE mismatch seems not to be the most determining reason for the differences in the observed spallation tendency. The differences in the nitride layer formation can also play a role, which has been the focus of various studies $[39,40]$, however, its definite role in the oxidation behaviour is not unambiguous. As far as spallation is concerned the results suggest that stronger generation of nitrides can cause enhanced spallation. The presence of $\mathrm{N}$ leads to the formation of a segmented nitride/oxide layer at the interface towards the substrate [41]. Such a structure causes stresses, which finally can trigger spallation.

The addition of 2 at.\% $\mathrm{W}$ in case of the IRIS alloy leads to a lower mass gain during isothermal exposure when compared to the 4822 alloy containing the same Al content and an equal amount of $\mathrm{Nb}$. The scale on the IRIS alloy is thinner than the scale on the other two alloys. Different to the other alloys is the presence of a compact alumina layer near the surface on the exposed IRIS sample, which is not so dominant on the 4822 material and even less distinct on the TNM specimen. For example, the alumina layer on the TNM specimen is more intersected by rutile than it is the case for the other two alloys. The element $\mathrm{Cr}$ is known to deteriorate the oxidation resistance of TiAl alloys. However, in combination with $\mathrm{Nb}$ this negative effect does not play a role as shown by comparison of the oxidation behavior of the 4822 alloy with that of a $\mathrm{Nb}$-free $\mathrm{Cr}$ containing alloy [42]. Therefore, $\mathrm{Cr}$ can be excluded as the main reason for the differences between the 4822 alloy and the IRIS alloy, whose oxidation behavior is quite astonishing. Despite the lack of $\mathrm{Nb}$, the mass gain of the IRIS alloy during isothermal or thermocyclic oxidation is the lowest when compared to the other two alloys. This is attributed to the dense formed alumina layer, which is stable even during thermocyclic exposure. This layer hinders the 
inward diffusion of $\mathrm{O}$ so that the substrate does not get oxidized in the same way as the TNM or 4822 alloy. This lower inward diffusion of $\mathrm{O}$ explains why the mixed scale underneath the alumina enrichment on the IRIS sample is the thinnest. Moreover, W can form oxidation states up to +6 and the incorporation of such a high valence cation within the oxide scale reduces the anion diffusion of oxygen through the oxide and, hence, increases the oxidation resistance. Additionally, the ionic radius of $\mathrm{W}$ is higher than the ones of Ti and $\mathrm{Al}$. This fact can also influence the oxygen diffusion through the oxide scale. The positive effect of $\mathrm{W}$ to form a dense alumina layer and alumina enrichment near the substrate [43], however, vanishes after a certain period of time when the oxide scale gets too thick. Then, during long thermal cycling cracks will form within the scale, which leads to enhanced $\mathrm{O}$ ingress. This causes accelerated damage of the substrate due to kinetic reasons of a fast $\mathrm{TiO}_{2}$ formation. This is why a marked inward attack was observed on some spots after $600 \mathrm{~h}$ of oxidation. Hence, the positive effect of 2 at. $\% \mathrm{~W}$ addition on the oxidation behavior does not last longer than $600 \mathrm{~h}$ at $900^{\circ} \mathrm{C}$.

Fluorine on the other hand triggers a long-term protection. Preliminary results have shown that the alumina layer after fluorine treatment is stable under thermocyclic conditions for several thousand hours even with a continuous $\alpha_{2}-\mathrm{Ti}_{3} \mathrm{Al}$ zone underneath [23]. The $\alpha_{2}$-phase usually forms a $\mathrm{TiO}_{2}$ rich mixed scale. In contrast, only a very small amount of $\mathrm{TiO}_{2}$ is formed on the fluorine treated samples during the incubation period. The alumina formation via the fluorine mechanism is described to be based on the predominant formation of gaseous Al-fluorides [21]. These compounds evaporate through micropores and microcracks at the interface metal/oxide and along the grain boundaries of the oxides. Their transformation towards alumina is at the end forced by the increased oxygen partial pressure, which has a very steep gradient towards the outer surface, i.e. 0.2 bar at the surface if oxidization takes place in air. Diffusion of O plays a minor role while $\mathrm{Al}$ diffusion is not involved in the $\mathrm{Al}_{2} \mathrm{O}_{3}$ formation. The following reactions describe the fluorine effect (eqs. 1-4). The fluorides form at the metal/oxide interface where the $\mathrm{O}$ partial pressure is very low. The partial pressures of the Al fluorides are several orders of magnitude higher than those of the Ti-fluorides if a defined amount of fluorine is applied [22]. The monovalent $\mathrm{AlF}_{(\mathrm{g})}$ is the predominant compound. This fluoride is finally oxidized to $\mathrm{Al}_{2} \mathrm{O}_{3}$ during to its outward diffusion due to the increasing $\mathrm{O}$ partial pressure (3). The enthalpies have been calculated with FactSage [44]. It can be seen that the enthalpy of fluoride formation is similar for $\mathrm{Al}$ and $\mathrm{Ti}$ but the enthalpy of oxide formation from the fluorides is higher for $\mathrm{AlF}_{(\mathrm{g})}$ (eq. 3) compared to $\mathrm{TiF}_{2(\mathrm{~g})}$ (eq. 4).

$$
\begin{array}{ll}
2 \mathrm{Al}_{(\mathrm{s})}+\mathrm{F}_{2(\mathrm{~g})} \rightarrow 2 \mathrm{AlF}_{(\mathrm{g})} & ; \Delta \mathrm{G}^{0}{ }_{900^{\circ} \mathrm{C}}=709 \mathrm{~kJ} / \mathrm{mol} \\
\mathrm{Ti}_{(\mathrm{s})}+\mathrm{F}_{2(\mathrm{~g})} \rightarrow \mathrm{TiF}_{2(\mathrm{~g})} & ; \Delta \mathrm{G}^{0}{ }_{900^{\circ} \mathrm{C}}=743 \mathrm{~kJ} / \mathrm{mol} \\
4 \mathrm{AlF}_{(\mathrm{g})}+3 \mathrm{O}_{2(\mathrm{~g})} \rightarrow 2 \mathrm{Al}_{2} \mathrm{O}_{3}+2 \mathrm{~F}_{2(\mathrm{~g})} & ; \Delta \mathrm{G}^{0}{ }_{900^{\circ} \mathrm{C}}=1190 \mathrm{~kJ} / \mathrm{mol} \\
\mathrm{TiF}_{2(\mathrm{~g})}+\mathrm{O}_{2(\mathrm{~g})} \rightarrow \mathrm{TiO}_{2}+\mathrm{F}_{2(\mathrm{~g})} ; \Delta \mathrm{G}^{0}{ }_{900^{\circ} \mathrm{C}}=13 \mathrm{~kJ} / \mathrm{mol}
\end{array}
$$

Fluorine is still present at the metal/oxide interface, which maintains the fluorine effect mechanism in a circular process [45]. Thus, alumina is even stable on top of the Al-lean $\alpha_{2}-\mathrm{Ti}_{3} \mathrm{Al}$ phase. The conditions for the formation of gaseous Al-fluorides totally differ from those of "normal" alumina formation, which is only based on cation and anion diffusion within the lattice [46]. The treatment was the same for all materials and the protective effect of fluorine was proven for all investigated alloys. The alumina layer on the TNM alloy is only slightly thicker than the layers found on 4822 and the IRIS alloy. 


\section{Summary}

The oxidation kinetic of three engineering $\gamma$-TiAl-based alloys was investigated during isothermal tests using thermogravimetric analysis. The untreated alloys, i.e. no prior fluorinetreatment was conducted, TNM and 4822 reveal similar mass gain behavior, while the IRIS alloy shows a significant lower mass gain. The first two alloys exhibit also similar behavior during thermocyclic exposure, but only for the first $120 \mathrm{~h}$. After this duration, spallation is observed that is more pronounced for the TNM alloy than for the 4822 alloy. On the other hand, the IRIS alloy reveals only very slight spallation. At all, the IRIS alloy exhibits a quite astonishing oxidation behavior, which is due to the formation of a dense alumina layer which is caused by the presence of 2 at. $\% \mathrm{~W}$.

However, after a fluorine treatment all alloys exhibit the so-called positive "fluorine effect". The presence of fluorine leads to the formation of a slow-growing alumina $\mathrm{Al}_{2} \mathrm{O}_{3}$ layer instead of a non-protective mixed $\mathrm{TiO}_{2} / \mathrm{Al}_{2} \mathrm{O}_{3} / \mathrm{TiN}$ scale. This alumina layer has the ability to protect the substrate against further oxidation and to suppress the mixed oxide scale formation. The results prove that the F-induced beneficial change in the oxidation mechanism can be applied to various intermetallic $\gamma$-TiAl based alloys, independent of the appearing phases, their chemical composition as well as processing history.

\section{References}

1. B. P. Bewlay, S. Nag, M. J. Weimer, Materials at High Temperatures 33 (2016) 549-559.

2. R. R. Boyer, J. C. Williams, in "Ti 2011", ed. L. Zhou, H. Chang, Y. Lu and D. Xu, Science Press, Beijing, 2012, pp. 10-19.

3. H. Clemens, S. Mayer, Adv. Eng. Mat. 15 (2013) 191-215.

4. S. Mayer, P. Erdely, F.D. Fischer, D. Holec, M. Kastenhuber, T. Klein, H. Clemens, Adv. Eng. Mat. 19 (2017) 1600735.

5. D. Hauptmann, Report MTU Aero Engines 1 (2013) 24.

6. V. Güther, M. Allen, J. Klose, H. Clemens, Intermetallics 103 (2018) 12-22.

7. V. Anil Kumar, R.K. Gupta, M.J.N.V. Prasad, S.V.S. Narayana Murty, J. Mat. Res. 36 (2021) 689-716.

8. A. Rahmel, P. J. Spencer, Oxid. Met. 35 (1991) 53-68.

9. J. M. Rakowski, F. S. Petit, G.H. Meier, F. Dettenwanger, E. Schumann, M. Rühle, Scripta Met. Mat. 33 (1995) 997-1003.

10. M. Schütze, "Protective oxide scales and their breakdown", Wiley, Chichester, 2007.

11. Y. Shida, H. Anada, Corr. Sci. 35 (1993) 945-953.

12. C. Leyens, in "Titanium and Titanium Alloys", ed. C. Leyens, M. Peters, Wiley/VCH, Weinheim, 2003, pp. 187-230.

13. P. Perez, J.A. Jiminez, G. Frommeyer, P. Adeva, Mat. Sci. Eng. A 284 (2000) 138-147.

14. S. Taniguchi, K. Uesaki, Y.-C. Zhu, Y. Matsumoto, T. Shibata, Mat. Sci. Eng. A266 (1999) 267-275.

15. D. Pilone, F. Felli, A. Brotzu, Intermetallics 43 (2013) 131-137.

16. R. Pflumm, A. Donchev, S. Mayer, H. Clemens, M. Schütze, Intermetallics 53 (2014) 4555 
17. Y. Shida, H. Anada, Ox. Met. 45 (1996) 197-219.

18. H. Anada, Y. Shida, J. Japan Inst. Metals 58 (1994) 1036-1043.

19. R. Pflumm, S. Friedle, M. Schütze, Intermetallics 56 (2015) 1-14.

20. A. Donchev, E. Richter, R. Yankov, M. Schütze, Intermetallics 14 (2008) 1168-1174.

21. A. Donchev, M. Galetz, in „Intermetallic Compounds“, ed. M. Aliofkhazraei, IntechOpen, London, 2018, pp. 73-96.

22. A. Donchev, B. Gleeson, M. Schütze, Intermetallics 11 (2003) 387-398.

23. A. Donchev, E. Richter, M. Schütze, R. Yankov, J. Alloys Comp. 452 (2008) 7-10.

24. B.P. Bewlay, S. Nag, A. Suzuki, M.J. Weimer, Mat. High Temp. 33 (2016) 549-559.

25. T. Voisin, J.P. Monchoux, C. Deshayes, M. Thomas, A. Couret, Met. Mat. Trans. 47A (2016) 6097-6108.

26. G. Molenat, M. Thomas, J. Galy, A. Couret, Adv. Eng. Mat. 9 (2007) 667-669.

27. A. Donchev, M. Schütze, R. Yankov, A. Kolitsch, W. Möller, in "Structural Aluminides for Elevated Temperatures", ed. Y.W. Kim, D. Morris, D. Yang, C. Leyens, TMS, Warrendale, 2008, pp. 323-332.

28. E. Berghof-Hasselbächer, S. Diliberto, P. Gawenda, P.J. Masset, G. Schmidt, M. Schütze, Prakt. Metallographie 47 (2010) 65-83.

29. T. Schmoelzer, S. Mayer, C. Seiler, F. Haupt, V. Güther, P. Staron, K,-D. Liss, H. Clemens, Adv. Eng. Mat. 13 (2011) 306-311.

30. J.L. Smialek, J.A. Nesbitt, W.J. Brindley, M.P. Brady, J. Doychak, MRS Symp. Proc. 364, ed. J. Horton, R.D. Noede, I. Baker, S. Hanada, MRS, Warrendale, 1995, pp. 12731284.

31. A. Gil, H. Hoven, E. Wallura, W.J. Quadakkers, Corros. Sci. 34 (1993) 615-630.

32. L. Mengis, A.S. Ulrich, P. Watermeyer, C.H. Liebscher, M.C. Galetz, Corros. Sci. 178 (2021) 109085.

33. Y. Shida, H. Anada, Ox. Met. 45 (1996) 197-218.

34. M.F. Stroosnijder, N. Zheng, W.J. Quadakkers, R. Hofman, A. Gil, F. Lanza, Ox. Met. 46 (1996) 19-35.

35. K.V.K. Rao, S.V.N. Naidu, L. Iyengar, J. Am. Ceram. Soc. 53 (1970) 124-126.

36. J.B. Wachtman, T.G. Scuderi, G.W. Cleek, J. Am. Ceram. Soc. 65 (1962) 319-323.

37. H.O. Pierson, "Handbook of Refractory Carbides \& Nitrides", Elsevier Science, Amsterdam, 2013.

38. J. Kumpfert, C. Leyens, in "Titanium and Titanium Alloys", ed. C. Leyens, M. Peters, Wiley/VCH, Weinheim, 2003, pp. 59-88.

39. N. Zheng, Q. J. Quadakkers, A. Gil, H. Nickel, Oxidation of Metals 44 (1995) 477-499.

40. P. Schaaf, Q. J. Quadakkers, N. Zheng, W. Wallura, A. Gil, Corrosion Science and Technology, 48 (1997) 28-34.

41. F. Dettenwanger, E. Schumann, M. Rühle, J. Rakowski, G.H. Meier, Ox. Met. 50 (1998) 269-307.

42. S.C. Huang, D.W. McKee, D.S. Shih, J.C. Chesnutt, Proc. Int. Symp. Intermet. Comp. JIMIS 6, ed. O. Izumi, JIM, Sendai, 1991, pp. 363-370

43. Y. Shida, H. Anada, Mat. Trans 35 (1994) 623-631.

44. C.W. Bale, P. Chartrand, S.A. Degterov, G. Eriksson, K. Hack, R. Ben Mahfoud, J. Melancon, A.D. Pelton, S. Petersen, Calphad 26 (2002) 189-228.

45. R.A. Yankov, A. Kolitsch, J. von Borany, F. Munnik, S. Gemming, A. Alexewicz, H. Bracht, H. Rösner, A. Donchev, M. Schütze, Adv. Eng. Mat. 16 (2014) 52-59. 
46. P. Kofstad, “High Temperature Corrosion”, Elsevier, London, 1988. 


\section{Figure captions:}

Figure 1: SEM/BSE images of the microstructures of the investigated alloys a) TNM, b) 4822 and c) IRIS

Figure 2a-d: TGA curves of the untreated materials during isothermal exposure (a), an untreated and F-treated TNM specimen (b) an untreated and F-treated 4822 specimen (c) and an untreated and F-treated IRIS specimen (d) at $900^{\circ} \mathrm{C}$ in dry synthetic air for $120 \mathrm{~h}$.

Figure 3: Mass change curves of the untreated and F-treated alloys during thermocyclic exposure at $900^{\circ} \mathrm{C}$ in laboratory air for $600 \mathrm{~h}(25 \mathrm{~h}$-cycle test $)$.

Figure 4a-c: Magnified images of the untreated materials after thermocyclic exposure at $900^{\circ} \mathrm{C}$ in laboratory air for $600 \mathrm{~h}$ a) TNM, b) 4822 and c) IRIS.

Figure 5a, b: SEM/SE images and embedded EDX spectra $(20 \mathrm{keV})$ of the surface of the untreated (a) and F-treated (b) TNM samples after thermocyclic exposure at $900^{\circ} \mathrm{C}$ under laboratory air for $600 \mathrm{~h}$ ( $25 \mathrm{~h}$-cycle test).

Figure 6a, b: XRD patterns of the surface of the exposed TNM samples a) without treatment and b) with fluorine both after $120 \mathrm{~h}$ of exposure at $900^{\circ} \mathrm{C}$ in dry synthetic air $\left(1=\mathrm{Al}_{2} \mathrm{O}_{3} / 2=\mathrm{TiO}_{2} /\right.$ $\left.3=\gamma-\mathrm{TiAl} / 4=\alpha_{2}-\mathrm{Ti}_{3} \mathrm{Al}\right)$

Figure 7a-c: SEM/BSE images of the mixed oxide scales on the untreated TNM sample (a), untreated 4822 sample (b) and untreated IRIS sample (b) after isothermal exposure at $900^{\circ} \mathrm{C}$ in laboratory air for $120 \mathrm{~h}$.

Figure 8: EPMA elemental distributions of the mixed oxide scale of untreated TNM sample after isothermal exposure at $900^{\circ} \mathrm{C}$ in laboratory air for $120 \mathrm{~h}$.

Figure 9: EPMA elemental images of the mixed oxide scale of untreated 4822 sample after isothermal exposure at $900^{\circ} \mathrm{C}$ in laboratory air for $120 \mathrm{~h}$.

Figure 10: EPMA elemental images of the mixed oxide scale of untreated IRIS sample after isothermal exposure at $900^{\circ} \mathrm{C}$ in laboratory air for $120 \mathrm{~h}$.

Figure 11a-c: SEM/BSE images of the mixed oxide scales on the untreated alloys after thermocyclic exposure for $600 \mathrm{~h}$ at $900^{\circ} \mathrm{C}$ in laboratory air, $\mathrm{a}=\mathrm{TNM}, \mathrm{b}=4822, \mathrm{c}=$ IRIS.

Figure 12a-e: SEM/BSE images of an area with accelerated attack (a) and corresponding EDX spectrum (c), the interface towards the substrate underneath the zone with accelerated attack (b) with corresponding EDX spectrum (d) and an overview image (e) of the untreated IRIS sample after 25 cycles, i.e. $600 \mathrm{~h}$, at $900^{\circ} \mathrm{C}$ in laboratory air. 
Figure 13a-c: SEM/BSE -images of metallographic cross sections of the F-treated materials (a) TNM sample, (b) 4822 sample and (c) IRIS sample after thermocyclic exposure at $900^{\circ} \mathrm{C}$ in laboratory air for 25 cycles, i.e. $600 \mathrm{~h}$.

Figure 14: EPMA elemental images of the mixed oxide scale of F-treated TMN sample after thermocyclic exposure at $900^{\circ} \mathrm{C}$ in laboratory air for $600 \mathrm{~h}$.

Figure 15: EPMA elemental images of the mixed oxide scale of F-treated 822 sample after thermocyclic exposure at $900^{\circ} \mathrm{C}$ in laboratory air for $600 \mathrm{~h}$.

Figure 16: EPMA elemental images of the mixed oxide scale of F-treated IRIS sample after thermocyclic exposure at $900^{\circ} \mathrm{C}$ in laboratory air for $600 \mathrm{~h}$. 


\section{Tables:}

Table 1: Final mass gain values of the isothermally exposed specimens.

Table 2: Elemental quantification (at.-\%) of the EDX spectra in Fig. 5. 
Graphical Abstract:

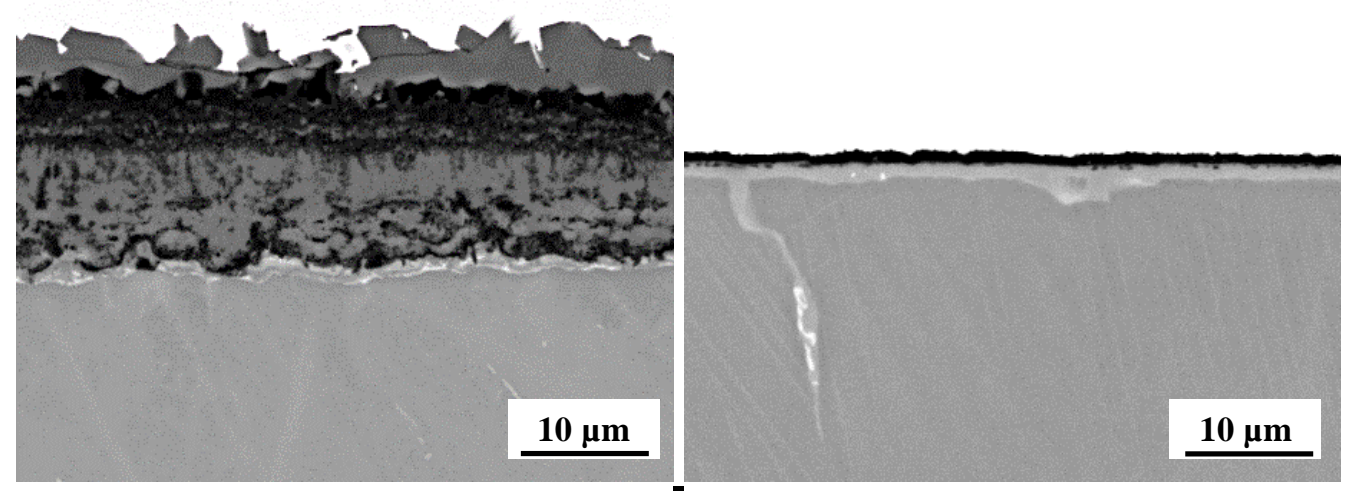

SEM/BSE images of untreated (left) and F-treated (right) 4822 samples after thermocyclic exposure at $900^{\circ} \mathrm{C}$ for $600 \mathrm{~h}$ in air. 